\title{
DNA-Methylation: Master or Slave of Neural Fate Decisions?
}

\author{
Stefan H. Stricker ${ }^{1,2,3 *}$ and Magdalena Götz ${ }^{2,3,4 *}$ \\ ${ }^{1}$ MCN Junior Research Group, Munich Center for Neurosciences, Ludwig-Maximilian-Universität, Munich, Germany, \\ ${ }^{2}$ Physiological Genomics, BioMedical Center, Munich, Germany, ${ }^{3}$ German Research Center for Environmental Health, \\ Ingolstädter Landstrasse 1, Germany and Biomedical Center, Institute of Stem Cell Research, Helmholtz Zentrum, \\ Ludwig-Maximilian-Universität, Munich, Germany, ${ }^{4}$ German Excellence Cluster of Systems Neurology, Munich, Germany
}

The pristine formation of complex organs depends on sharp temporal and spatial control of gene expression. Therefore, epigenetic mechanisms have been frequently attributed a central role in controlling cell fate determination. A prime example for this is the first discovered and still most studied epigenetic mark, DNA methylation, and the development of the most complex mammalian organ, the brain. Recently, the field of epigenetics has advanced significantly: new DNA modifications were discovered, epigenomic profiling became widely accessible, and methods for targeted epigenomic manipulation have been developed. Thus, it is time to challenge established models of epigenetic gene regulation. Here, we review the current state of knowledge about DNA modifications, their epigenomic distribution, and their regulatory role. We will summarize the evidence suggesting they possess crucial roles in neurogenesis and discuss whether this likely includes lineage choice regulation or rather effects on differentiation. Finally, we will attempt an outlook on how questions, which remain unresolved, could be answered soon.

Keywords: DNA methylation, neurogenesis, DNA modification, epigenomics, epigenetics

\section{DNA METHYLATION AND OTHER FORMS OF DNA MODIFICATIONS}

In 1948, Rollin Hotchkiss used paper chromatography to separate and quantify the components of DNA. To his surprise he detected not only the four nucleo-bases thymine, adenine, cytosine, and guanine, but also a "minor constituent designated epicytosine [with] a migration rate somewhat greater than that of cytosine" (Hotchkiss, 1948). As Hotchkiss had already suspected, epicytosine turned out to be a methylated form of cytosine. Thus, the first description of an epigenomic mark occurred only few years after DNA has been identified as the carrier of genetic information (Avery et al., 1944) and years before its structure has been resolved (Watson and Crick, 1953). Coincidently to these biochemical insights, first conceptual ideas arose attempting, to explain, how a single set of genetic information could give rise to the pleiotropy of cellular phenotypes (Waddington, 1957). From these early days on, epigenomic marks and epigenetic phenotypes have been closely intertwined, which lead to great discoveries but also to misconceptions, such as the perception, these two terms, epigenetic ("heritable traits that have their origin not in the DNA sequence") and epigenomic ("reversible marks, modifications and features of DNA-implicated in epigenetic traits") would be equivalent.

Today we know that many more DNA modifications exist. Additionally to the mark usually meant by the phrase "DNA methylation" [the methylation of cytosine at position C5 
(C5-methylcytosine, 5mC)], the same base can also occur methylated on other positions [e.g., N3-methylcytosine $(3 \mathrm{mC})$ ]. $3 \mathrm{mC}$ is, however, thought to represent rather a product of DNA damage than a bona fide information carrier (SadakierskaChudy et al., 2015). But not only cytosine can be targeted by methylation, also adenine [N6-methyladenine, $(6 \mathrm{~mA}) ;(\mathrm{Wu}$ et al., 2016)]. On top, new DNA modifications on the position C5 have been discovered recently, which are generated by DNA demethylation pathways (Booth et al., 2015, Figure 1). The first of these $5 \mathrm{mC}$ oxidation products to be reported was 5 hmC (C5-hydroxymethylcytosine) (Kriaucionis and Heintz, 2009; Tahiliani et al., 2009); 5fC (C5-formylcytosine), and 5caC (C5-carboxylcytosine) followed later. Although $5 \mathrm{hmC}$ has been described to occur in animal tissues (e.g., mouse brains) already in the 70s (Penn et al., 1972), its relevance was not recognized as it was widely interpreted as a product of DNA damage (Privat and Sowers, 1996). Today we know that $5 \mathrm{hmC}$ and $5 \mathrm{caC}$ are not necessarily transient marks occurring solely in a sequence of chemical reactions; instead they can appear quite stable at least under some circumstances (Bachman et al., 2014, 2015).

In the following, we will give a short overview about the distribution of DNA modifications and discuss how they are established. We will then present the suggested roles for DNA modifications in gene expression control and review how those have been implicated into regulating lineage decisions during brain development. We finish with re-evaluating the scientific evidence for DNA methylation marks controlling neurogenesis and discuss recent technical advances to study their function at precise sites in the genome. Although we mention several biological processes and all known DNA modifications in this review, we will focus on the role C5-methylcytosine plays in neurogenesis and neuronal maturation.

\section{EPIGENOMIC DISTRIBUTIONS OF DNA MODIFICATIONS}

Although DNA modifications are common in bacteria (e.g., m6A, N6-methyladenine; m5C, C5-methylcytosine; m4C,
C4-methylcytosine) (Chen et al., 2014), many eukaryotic model systems have no or only traces of 5C methylation. Neither Saccharomyces cerevisiae nor Caenorhabditis elegans possess this epigenomic mark (Shin et al., 2014). In Drosophila melanogaster it is very rare and has only lately been confirmed (Lyko et al., 2000). This remarkable absence of canonical DNA methylation in the three most frequently used genetic model systems might be one reason its universal significance for gene expression and cellular phenotypes is still not known. Consequently, today, 70 years after its discovery, the discussion about how frequent functional DNA methylation marks are, is still ongoing (Stricker et al., 2017). In this context it should be mentioned, however, that the genomes of Caenorhabditis elegans and Drosophila melanogaster have recently shown to possess significant levels of m6A (Greer et al., 2015; Zhang et al., 2015).

In mammalian cells $\mathrm{m} 5 \mathrm{C}$ is rather frequent it occurs mainly in pairs of CpGs, in which between 80 and $90 \%$ of cytosines are methylated (Hon et al., 2013). Interestingly, those 10-20\% CpGs found to be unmethylated are not distributed randomly throughout the genome, but concentrate on so called $\mathrm{CpG}$ islands, which mostly coincide with gene promoters. Indeed, around half of mammalian transcripts begin in a CpG island (Bird, 2002). Until recently, it was believed that $5 \mathrm{mC}$ occurs in mammalian cells exclusively in the CpG context. That this is not necessarily the case has been shown with the help of new methods for epigenomic analysis of DNA modifications (Figure 2): first, in human pluripotent stem cells, in which $25 \%$ of m5C occurs at $\mathrm{CpH}$ sites (with $\mathrm{H}=\mathrm{A}, \mathrm{C}$, or T) (Lister et al., 2009), later this has been found also in (mouse and human) brain samples. Other tested somatic cells are, as far as we know, mostly devoid of such non-CpG methylation as far as we know (Xie et al., 2012; Lister et al., 2013). Similarly to non-CpG methylation, C5-hydroxymethylcytosine has also been first described in DNA derived from pluripotent and brain cells (Kriaucionis and Heintz, 2009; Tahiliani et al., 2009). Especially hypothalamus, cerebral cortex, and hippocampus have been reported to be rich sources of hm5C (Munzel et al., 2010), occurring almost at the rate of one sixth of m5C (Shin et al., 2014), often on enhancers (Yu et al., 2012). N6-methyladenine was found in mouse ES cells, in which

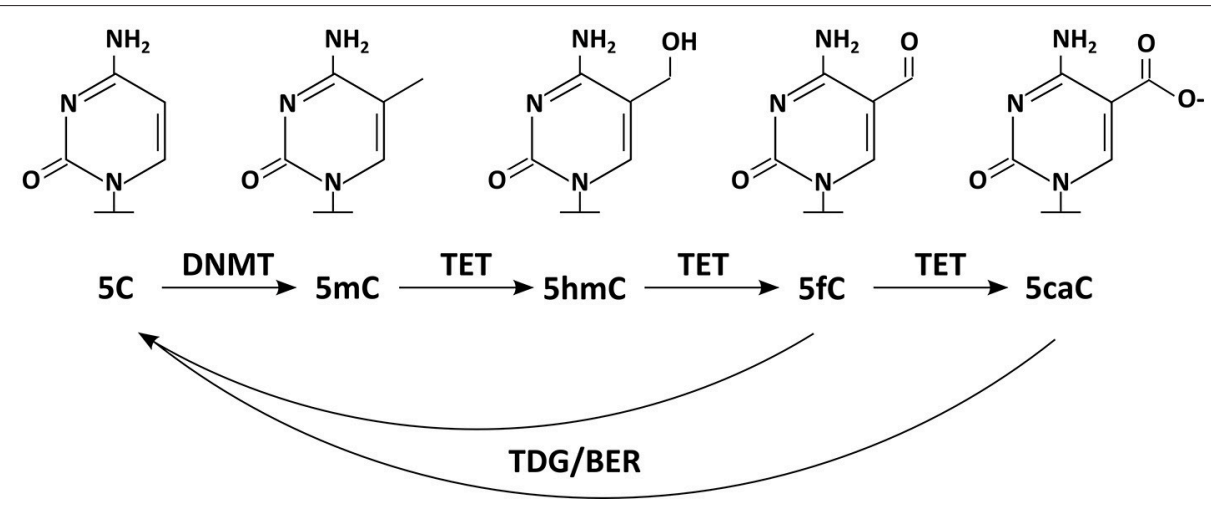

FIGURE 1 | Chemical structures of DNA modifications: five DNA modifications and relevant enzymes are depicted. DNMTs methylate 5C resulting in 5mC, which can be further modified by TET enzymes to $5 \mathrm{hmC}, 5 \mathrm{fC}$, and $5 \mathrm{caC}$. Enzymes of the TDG/BER pathway have been implicated in removal of the DNA modifications. 


\section{A Conversion based detection methods}

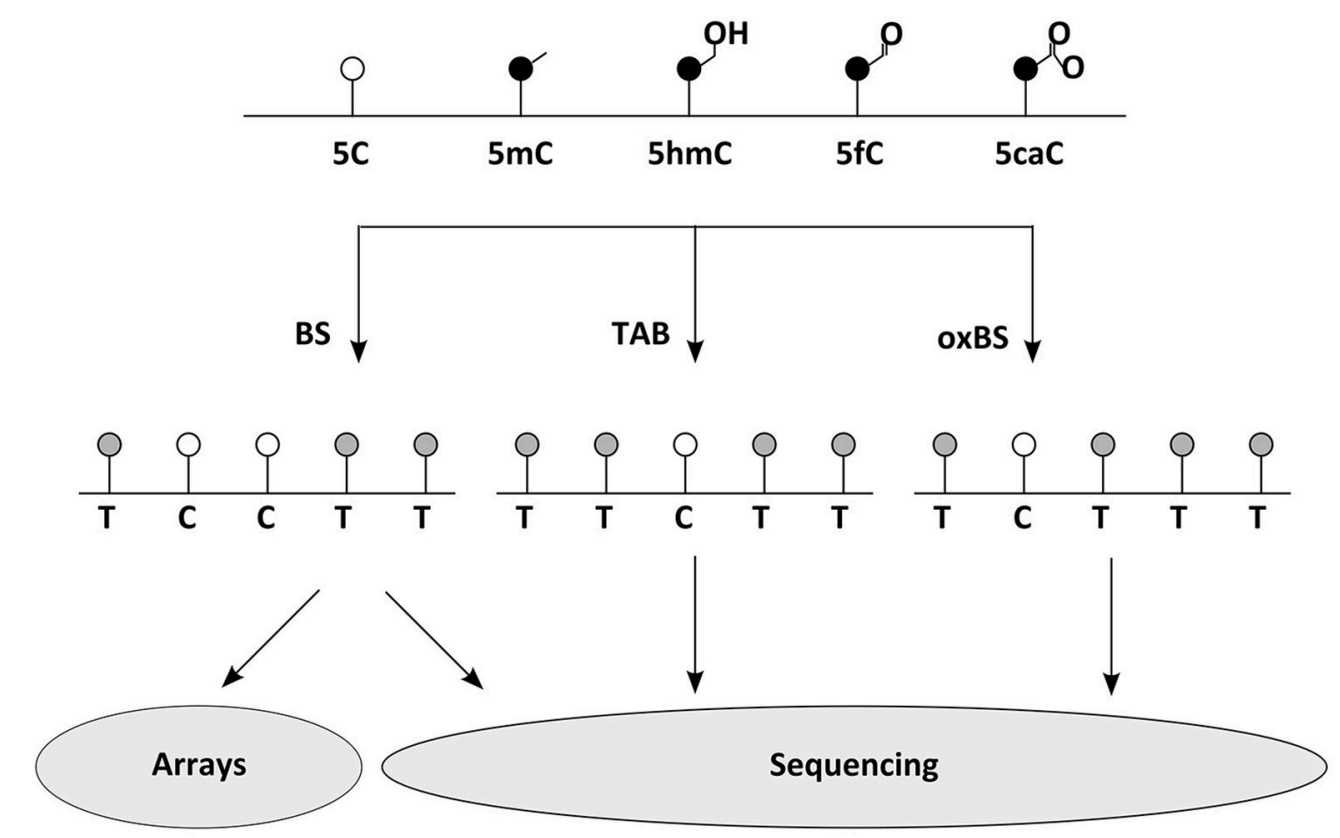

B Antibody based detection methods
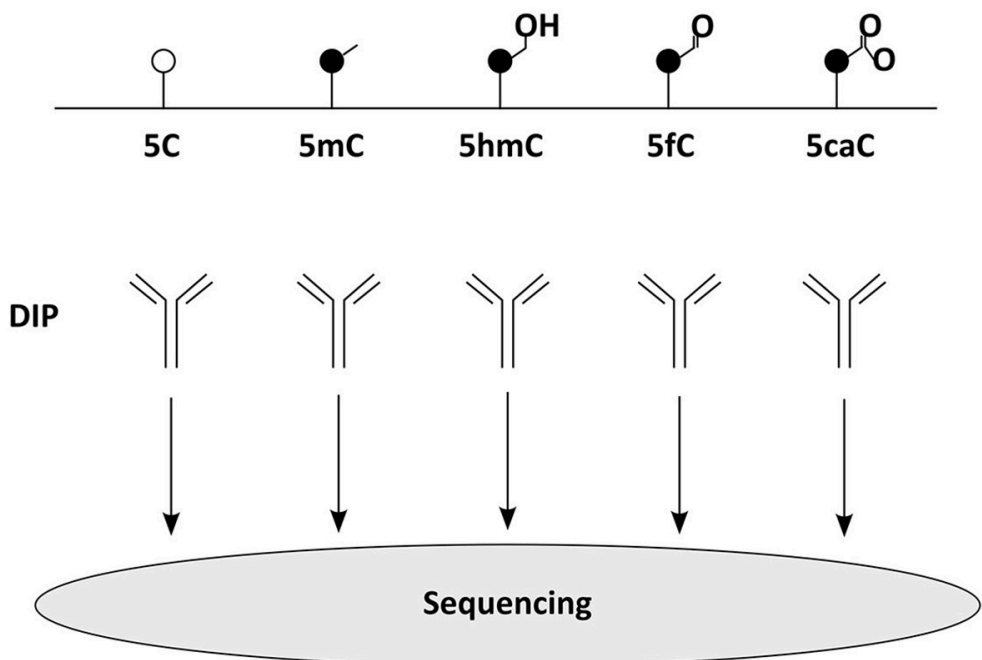

FIGURE 2 | Common methods for widespread detection of DNA modifications. (A) Conversion based detection methods. Bisulfite (BS) sequencing, oxidative bisulfite (oxBS) sequencing, and Tet assisted BS (TAB) sequencing enable the epigenomic distinction of 5C, 5mC, and 5hC, while similar techniques separating $5 f C$ and 5 caC have been developed as well (Plongthongkum et al., 2014). Sequence below indicates readout expected in NGS. For comprehensive analysis of DNA modifications several detection methods must be combined. (B) Antibody based detection methods. DNA Immunoprecipitations (DIP) using modification specific antibodies allow the quantitative analysis of epigenomic distribution (making use of NGS or arrays). meDIP (methylated DNA immunoprecipitation) has been the archetype of this methodology (Weber et al., 2005), but several variants for other DNA modifications have been reported as well recently (comprehensively reviewed in Plongthongkum et al., 2014). 
it occurs particularly on young LINE elements; they themselves are enriched on the X-chromosome (Wu et al., 2016).

\section{ESTABLISHMENT AND REMOVAL OF DNA MODIFICATIONS}

DNA methylation is catalyzed by a group of enzymes, the DNA methyltransferases, which catalyze the transfer of a methylation residue from S-adenosyl-L-methionine to $\mathrm{C} 5$ of cytosine. In mammals these consist of Dnmt3a and Dnmt3b, the de novo methyltransferases and Dnmt1, that maintains methylation through the cell cycle by copying CpG methylation patterns from the mother to the newly synthesized strand. Rodents have recently been shown to possess an additional de novo DNA methyltransferase, Dnmt3c, evolved through a gene duplication of Dnmt3b (Barau et al., 2016). The mammalian enzyme responsible for adenine methylation is currently unknown. Dnmt3a has been reported to occur in two different forms, due to alternative promoter usage. Although this is not uncommon for protein coding genes, it might be relevant for the methylome, since in cell lines Dnmt3al (the full length protein) and Dnmt3a2 (the short isoform) have been reported to occupy very different locations in chromatin. While Dnmt3al is found mainly in heterochromatin, Dnmt3a2 is associated with euchromatic regions (Chen et al., 2002). The two remaining members of the Dnmt family, $3 \mathrm{~L}$ and 2, are paralogs, which either lost enzymatic activity or methylate RNA (Goll et al., 2006; Ooi et al., 2007). While the de novo enzymes Dnmt3a and Dnmt3b are necessary to set DNA methylation marks (on CpG and likely also nonCpG positions) (Guo et al., 2014), Dnmt1 ensures its long term inheritance. It is acting on hemi-methylated DNA, occurring after DNA replication (or DNA repair) and transfers a methyl group to the cytosine on the unmethylated strand. Obviously, this depends on the palindromic base composition of CpG dinucleotides. $\mathrm{mCpH}$ sites lack a cytosine residue on the second DNA strand and thus, are certainly asymmetrically inherited to the progeny of pluripotent and neural stem cells. Whether this has however, any functional consequence has remains to be shown.

That Dnmt1 constantly antagonizes passive DNA demethylation is widely accepted. Whether there are any active processes selectively removing DNA methylation marks from certain epigenomic locations has been a controversial issue for a long time. Over the last decades there have been a series of reported findings of DNA demethylases (wittily summarized by Ooi and Bestor, 2008). In contrast to those, recent candidates have been received more favorably (Wu and Zhang, 2010). Today it is widely accepted, that a number of enzymes contribute on the de-methylation of $5 \mathrm{mC}$. First of all the members of the ten-eleven translocation family of enzymes (Tet1, Tet2 and Tet3) oxidize $5 \mathrm{mC}$ to $5 \mathrm{hmC}$. But Tet activity does not necessarily stop at this point, as these enzymes can further oxidize $5 \mathrm{hmC}$ to $5 \mathrm{fC}$ and subsequently to $5 \mathrm{caC}$ (Figure 1) (He et al., 2011; Ito et al., 2011). These marks are then thought to be lost passively or removed by the thymine DNA glycosylase (TDG), a forerunner of the base excision repair (BER) (Yu et al., 2012; Zhang et al.,
2012). Also other proteins and enzymes involved in DNA repair (e.g., GADD45/AID/APOBEC) have frequently been implicated in active DNA de-methylation (Rai et al., 2008; Bhutani et al., 2010, 2011), although their contributions to global methylomic changes are still being discussed (Nabel et al., 2012).

\section{GENERAL CONCEPTS FOR POTENTIAL FUNCTIONS OF DNA MODIFICATIONS}

DNA methylation has been implied in regulation of gene transcription already in the late 60s (Harrisson, 1971; Scarano, 1971; Holliday and Pugh, 1975; Riggs, 1975) and often still is; although it has become clear that it likely plays a much less general role than believed originally. But why has DNA methylation become the one epigenomic mark most frequently connected to epigenetic gene silencing in the first place? There are plenty of answers to this question, which we are neither able to discuss fairly, nor to list comprehensively; we think however, that most of the concepts and experimental evidence gained during the decades can be grouped into four types, which we will address below. First, the biochemical features of DNA methylation, its life cycle and inheritance make it a prime candidate for a developmental epigenetic mark; second, global correlations between the presence of DNA methylation and the activity state of DNA in the nucleus do occur; third, DNA methylation is necessary for normal animal development and finally, on some individual model loci a functional effect of DNA methylation on restricting transcription is clearly evident. Hereafter, we will discuss the evidence for the above criteria in establishing the previous model, namely a role of DNAmethylation in repressing alternative fates. Subsequently we will proceed to discuss experimental evidence testing this model. Data from pluripotent stem cell differentiation and mouse models in vivo (section Mouse Models) demonstrate that no fate switch to an alternative fate occurs even when most or all of methylation marks have gone (see section Mouse Models). Conversely, phenotypes appear late in brain development, often at postnatal stages, indicating rather that maturation processes are affected (Tables 1, 2).

\section{The Life Cycle of DNA Methylation Levels and Its Inheritance}

Since decades it is relatively undisputed that mammalian development has to provide a molecular memory restricting the options of each individual cell to express or adopt cell identities. Until recently, cellular potency was believed to be a one way street, with continuously less choices as development progresses. This has been put in a nutshell by the iconic depiction of the epigenetic landscape conceived by Waddington (1957). Although we know today, that we can revert development (Takahashi and Yamanaka, 2016) or provide direct shortcuts (Masserdotti et al., 2016), the basic question remains: What informs and restricts cellular identity during development? Very early on DNA methylation has been considered to be the prime candidate fulfilling this role. The reason for this has much to do with the dynamics of the mark itself as $\mathrm{m} 5 \mathrm{C}$ is a quite stable 
TABLE 1 | Published knockout mouse models and their reported phenotype during brain development and in the adult brain.

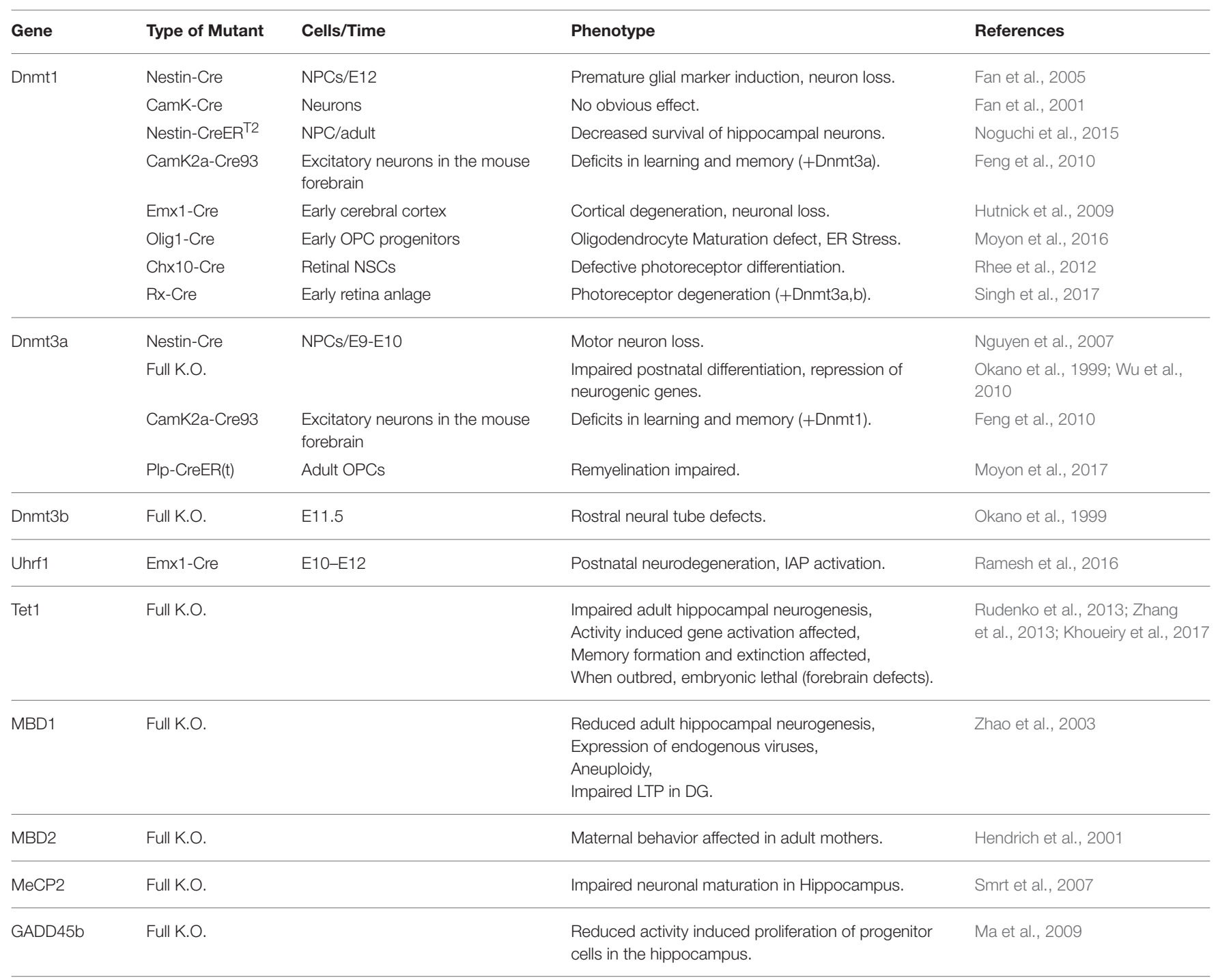

modification. Many m5C marks are set early in development (some even in the germ line, e.g., the imprints), but can often still be found in somatic cells. This stability is mainly provided by Dnmt1, which faithfully copies the methylation signature from the mother strand after each round of DNA replication. Despite its heritability over cell divisions, DNA methylomes also undergo significant changes during development, both globally and locally. A good example for global methylation changes is occurring during early embryogenesis. Sperm and oocyte each show high overall methylation levels. During the first cell divisions of the zygote, DNA methylation gets remodeled. Both, the maternal and the paternal epigenome get de-methylated, interestingly, however, with very different dynamics. While the paternal genome is immediately actively demethylated, the maternal genome undergoes passive DNA demethylation during continuous DNA replications (Messerschmidt et al., 2014). Thereafter, rapid re-methylation occurs on both genomes with the blastocyst stage, coincidently at the time cells loose totipotency and specify (Reik et al., 2001). Even though such dramatic changes are not recurring later in development; there are plenty local DNA methylation changes occurring in each cellular lineage, resulting in rather specific methylomes (Bernstein et al., 2007), which can not only be used to predict cell type, but even age (Horvath, 2013).

\section{Correlations between DNA Methylation and Transcription}

Early on it has been noticed that some DNA methylation changes occurring during development can correlate to transcriptional changes. The most impressive example, maybe because of its scale, is the hypermethylation on $\mathrm{CpG}$ island promoters found on inactivated $\mathrm{X}$-chromosomes in female mammalian cells (Lock et al., 1986; Singer-Sam et al., 1990), while the genetically identical copies on the active X-chromosome remain unmethylated. But also promoters of lineage specific genes, 
TABLE 2 | Predictions and experimental support of two models for main function of DNA-methylation in neurogenesis.

\begin{tabular}{|c|c|c|c|}
\hline Predictions model 1 & Met (+)/unmet (-) & Predictions model 2 & Met/unmet \\
\hline Early phenotype & - & $\begin{array}{l}\text { Late (postnatal) } \\
\text { phenotype }\end{array}$ & + \\
\hline $\begin{array}{l}\text { Appearance of } \\
\text { alternative fate }\end{array}$ & - & $\begin{array}{l}\text { Maintenance of } \\
\text { immature hallmarks }\end{array}$ & + \\
\hline $\begin{array}{l}\text { mRNA up-regulation } \\
\text { of alternative cell fate } \\
\text { genes }\end{array}$ & -(except GFAP) & $\begin{array}{l}\text { Failure to } \\
\text { down-regulate } \\
\text { progenitor-specific } \\
\text { mRNas }\end{array}$ & + \\
\hline
\end{tabular}

Model 1: DNA-methylation represses alternative fates vs. Model 2: DNA-methylation represses immature hallmarks to allow full maturation.

like MyoD or various globins, being studied since decades in primary and immortalized cells, have been found to attract DNA methylation when the respective genes get downregulated (Jones et al., 1990). More recently, these concepts have been refined, as it has been reported that those DNA methylation changes occurring during development and correlating to transcriptional differences among tissue types, do rarely involve entire CpG islands, but more often their mere borders (Irizarry et al., 2009). It should, however be mentioned, that most methylated sites in the genome lack predictive value and quite some methylated loci correlate rather to active transcription than gene silencing (Niesen et al., 2005; Irizarry et al., 2009; Bahar Halpern et al., 2014; Zhu et al., 2016).

\section{Genetic Manipulation of DNA Modifications}

Further hints into the functional relevance of DNA modifications were given by the generation of genetically modified mouse lines lacking parts of the machinery necessary for their deposition or removal. Thus, it has been shown that the ability to set and propagate DNA methylation marks is absolutely essential to undergo normal embryonic development, since animals lacking the de novo DNA methyltransferases Dnmt3a and b or the maintenance methyltransferase Dnmtl are not viable (Li et al., 1992; Okano et al., 1999). In contrast to this, the consequences of losing members of the Tet family of enzymes seem less severe. ESCs and mice lacking Tet1 [showing a considerable loss of $5 \mathrm{hmC}(\sim 20-40 \%)]$ are overall viable and only few genes are significantly mis-regulated (Dawlaty et al., 2011), although it has been reported that in non-inbred mice Tet1 is essential for embryogenesis (Khoueiry et al., 2017). A combined loss of Tet1 and 2 lead to a larger number of intermittent phenotypes, but mice lacking both proteins can be born viable and fertile (Dawlaty et al., 2013). Only when all three Tet proteins are depleted differentiation of pluripotent cells is largely impaired possibly due to dysregulation of important developmental genes (Dawlaty et al., 2014). Also depletion of the TDG affects animal development and accumulation of erroneous DNA methylation marks which is compatible with its suggested role in the DNA de-methylation pathway. However, reported changes are comparatively moderate and involve mostly genes known to swiftly attract DNA methylation, like the Hox genes (Cortazar et al., 2011).

\section{Model Systems of DNA Methylation Function}

Several model systems have over the years suggested a direct role for DNA methylation in transcriptional regulation. An early example is the in vitro methylation of DNA which has been shown to prevent transcription of exogenous copies of globin genes when transfected into mammalian cells (Busslinger et al., 1983). But also the discovery of genomic imprinting, a phenomenon of parental specific gene expression in the embryonic or adult offspring (Barlow et al., 1991; Bartolomei et al., 1991; Ferguson-Smith et al., 1991), delivered much needed evidence. It has been found that loci containing genes with imprinted expression contain a differentially methylated region, established through differences in gametic methylation patterns, which serve as imprinting control regions (ICEs). Genetic approaches resulting in loss of ICEs, imprinted DMRs or global DNA methylation eliminate parental specific gene expression, strongly suggesting a direct functional role for these DNA methylation marks in imprinted gene regulation (summarized in Barlow and Bartolomei, 2014).

\section{THEORETICAL MODELS OF TRANSCRIPTIONAL REGULATION BY DNA MODIFICATIONS}

How DNA methylation influences transcription was long elusive. The mechanisms by which DNA methylation of ICEs regulate imprinted gene expression vary and span from controlling expression of long non-coding RNAs (Lyle et al., 2000; Seidl et al., 2006) to interfering with the binding of the common chromatin protein CTCF on insulator elements (Bell and Felsenfeld, 2000). The most popular model for the effect of DNA methylation entails (consistent with active genes containing many $5 \mathrm{mC}$ residues in their bodies) that DNA methylation is not directly interfering with transcription. One common assumption is that it is rather the DNA binding affinity of transcription factors which is influenced by DNA methylation (Tate and Bird, 1993; Zhu et al., 2016). While many transcription factors are thought to be impaired by DNA methylation, some special transcription factors bind methylated DNA specifically (Figure 3). In this model, the group of proteins involved in gene regulation by DNA methylation can be divided in writer (e.g., the aforementioned DNMTs), eraser (e.g., TET proteins), and reader proteins. The latter can sense the presence of DNA methylation marks and respond with altered DNA binding affinity. Characterization of methyl binding proteins was a tedious task that is still ongoing today. Firstly discovered was a family of transcription factors defined by the possession of a protein domain, shown to prevalently bind to $5 \mathrm{mC}$ containing DNA in vitro. This so called MBD (methyl CpG binding domain) family of transcription factors has five known members (MBD1, MBD2, MBD3, MBD4, and MeCP2) (Hendrich and Bird, 1998; Zhu et al., 2016). Recent technological development has enabled the genome-wide characterization of their DNA binding features and elucidated methylation dependent and (particularly in the 


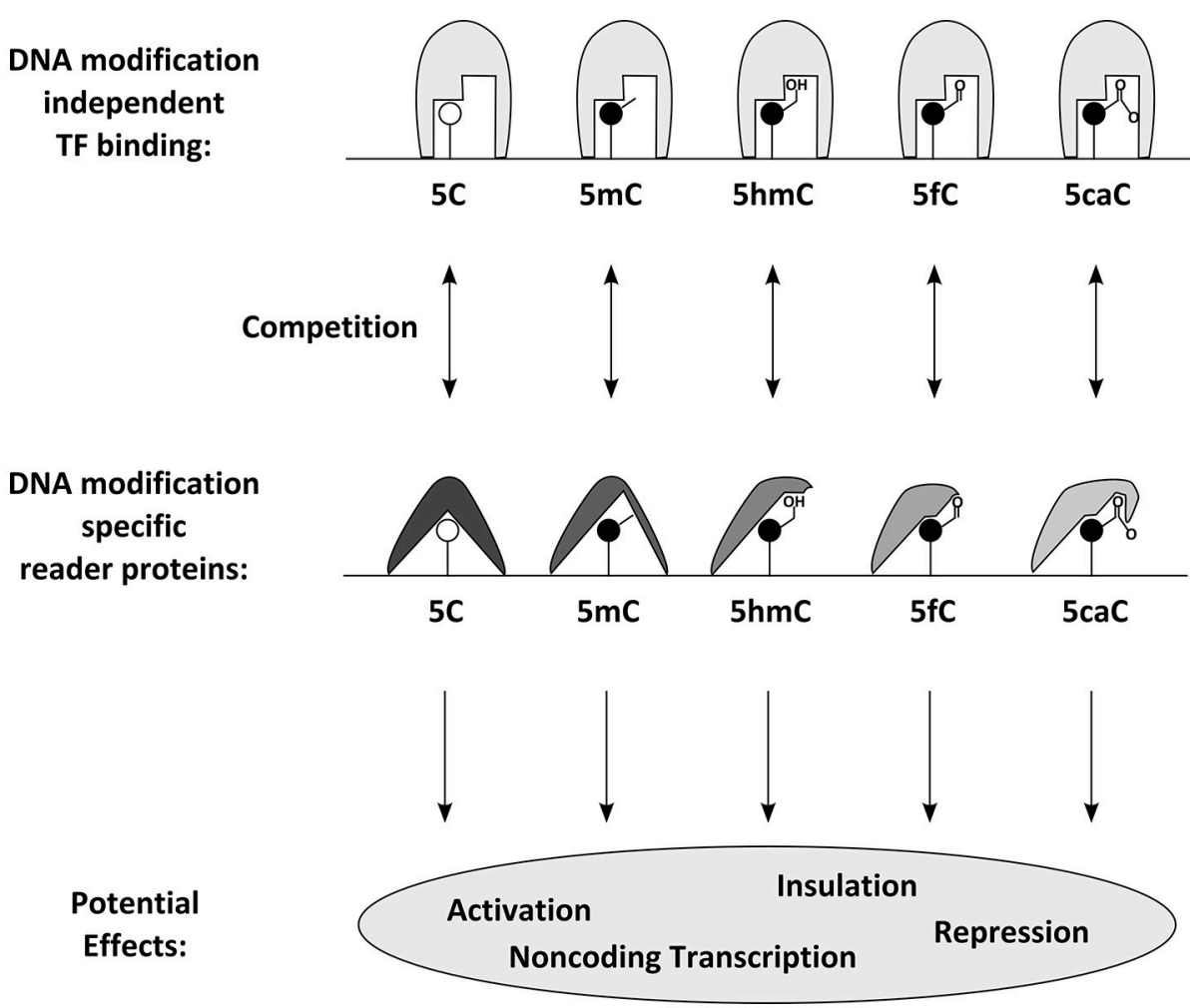

FIGURE 3 | Proposed molecular effects and consequences of DNA modifications: DNA modifications can be specifically bound by reader proteins. Those can either have a direct effect or compete with DNA modification independent transcription factors and thus influence transcription through gene activation, repression, non-coding transcription or insulation.

case of MBD3) independent DNA binding (Baubec et al., 2013). Complementary approaches helped discovering a large series of new candidate proteins that in vitro bind at least some of their possible binding motives specifically in the methylated form (comprehensively reviewed in Zhu et al., 2016), including many classical transcription factors like the pioneering factors Klf4 (Hu et al., 2013) and Kaiso (Prokhortchouk et al., 2001). A specialty among known methylation binding transcription factors is Uhrf1, a critical partner of Dnmt1, as it has been shown to recognize hemi-methylated DNA in its binding motive (Fang et al., 2016). Recent approaches aiming to discover reader proteins also for other DNA modifications. These efforts resulted in candidate lists for 5hmC- (e.g., Uhrf1 and Uhrf2), $5 \mathrm{fC}$ - (e.g., members of the NuRD complex), and 5caC-binding proteins (Frauer et al., 2011; Iurlaro et al., 2013; Spruijt et al., 2013) and indicated that MeCP2 is binding $5 \mathrm{mC}$ in both, $\mathrm{CpG}$ and $\mathrm{CpH}$ sites as well as other cytosine modifications (Mellen et al., 2012; Guo et al., 2014; Gabel et al., 2015). While much needs to be learnt about the in vivo roles of these reader proteins and few have been investigated in the context of neurogenesis and DNA methylation so far, recent analysis of Uhrf1 supports its key role in DNA-methylation homeostasis during development and reveals key requirements for later neuronal differentiation processes (Ramesh et al., 2016).

\section{Arguments against Global Roles}

Classical epigenetic research on model loci has provided functional examples and mechanistic models; through epigenomic approaches we can acknowledge how complex and dynamic epigenomes present themselves. Thus, to date the most pressing question in epigenetics is not so much, whether chromatin models of epigenetic gene regulation are correct, but rather how ubiquitous their functional relevance is; it is, for example, completely unclear, how many genes (and phenotypes) are significantly regulated by DNA modifications during development and disease. This is especially relevant for DNA methylation, which is rather frequent throughout the genome and has been extensively mapped. Interestingly, however, quite some data argues against the idea that the aforementioned models could be easily translated to any locus or transcriptional unit.

One of the earliest arguments against a ubiquitous role for DNA methylation in gene regulation was the finding that most epigenetically silenced promoters do not appear heavily methylated during development and, related to this, that those that do, often gain DNA methylation after gene expression is lost (Bird, 2002). But there is not only evidence that developmental gene silencing does not depend on DNA methylation changes, recent approaches using cancer tissue derived induced pluripotent stem cells suggest also that removal 
A

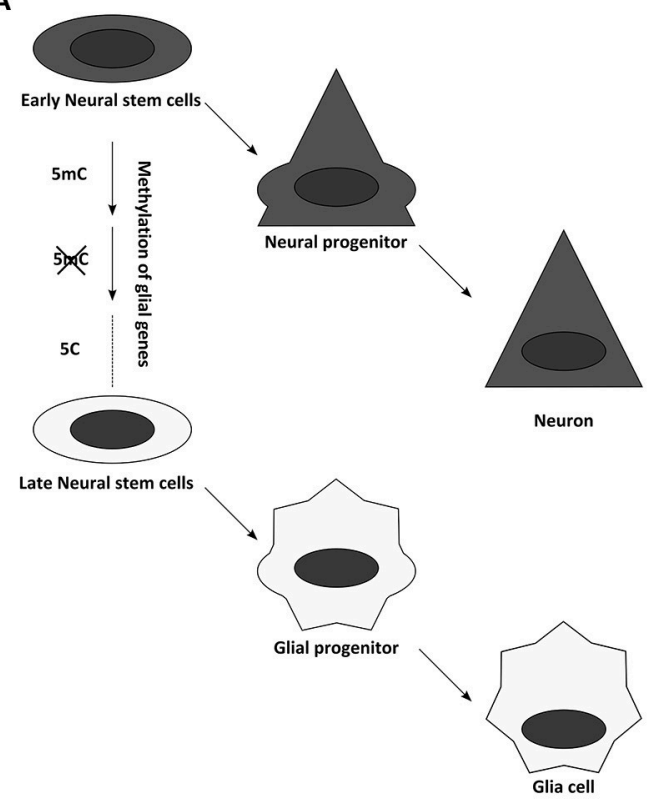

C

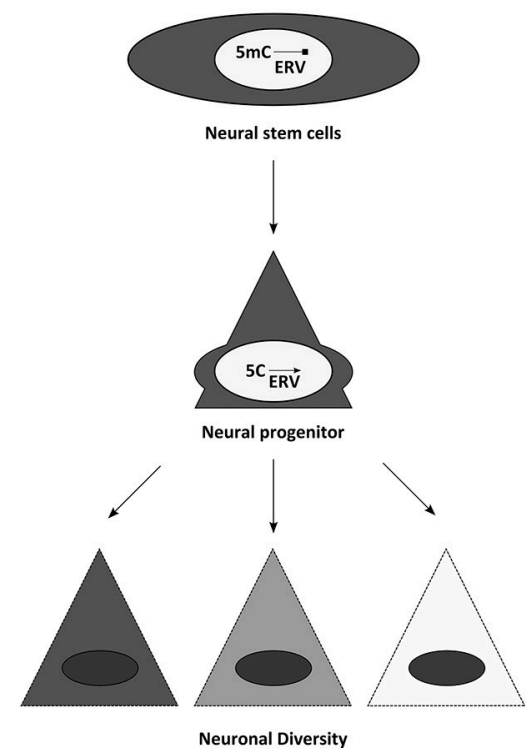

B

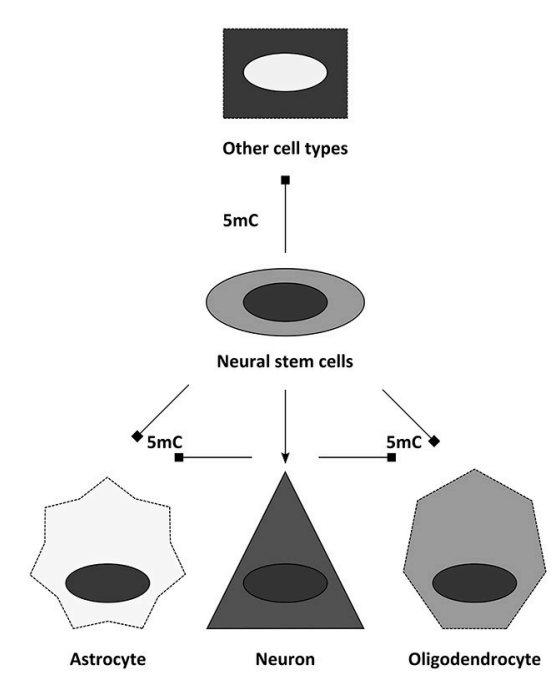

D

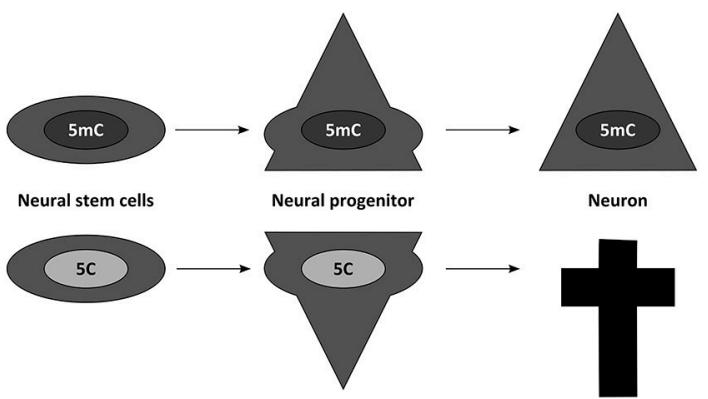

FIGURE 4 | Suggested influences of DNA methylation on neurogenesis. (A) Temporal progression of DNA methylomes might influence the potential of neural stem and progenitor cells. (B) Cell specific methylomes, here $5 \mathrm{mC}$ for simplification, might be responsible for neural cell identities. They could not only influence lineage choices, but might also simultaneously block alternative fates. (C) Through controlling activity of transposon derived sequences, DNA methylation has been implicated in contributing to neuronal diversity. (D) Global alterations of DNA modifications often result in cell death during differentiation.

of disease associated DNA methylation marks does not influence tumorigenicity of cancer cells significantly (Stricker et al., 2013; Chao et al., 2017). The most convincing argument might, however, come from genetically engineered embryonic stem cells lacking all six active copies of DNA methyltransferases [Dnmt1, Dnmt3a and Dnmt3b, Dnmt3c is not expressed in embryonic stem cells (Barau et al., 2016)]. These triple knockout ESCs have undetectable levels of DNA methylation in their genome. Surprisingly these cells are not only viable and macroscopically normal; they also possess very few misregulated genes. Moreover, as subsequently revealed by DNAse hypersensitive site analysis, very few transcription factors change their binding spectrum once DNA methylation is lost in these cells (Domcke et al., 2015). Similarly unexpected is the finding, that the complete loss of TET proteins in differentiating ESCs only results in a moderate increase of $5 \mathrm{mC}$ (Dawlaty et al., 
2014). These and other findings suggest that our current models of epigenetic gene regulation might be incomplete and have to be revisited in order to elucidate the function of DNA modifications.

\section{DNA METHYLATION IN NEUROGENESIS}

The above data prompt the question of how important DNA methylation would be in development. Development can be seen as a series of cellular fate restrictions and hence DNA methylation has been suspected to be involved in these processes. For example, neural stem cells (NSCs) become progressively restricted in the generation of neurons and later retain only the potential to generate glial cells in most brain regions (Figure 4A). Interestingly, the earliest restriction in fate is spatial and special to the nervous system as it is mediated by patterning and occurs in regard to the region the NSCs reside in (Kiecker and Lumsden, 2005). Even prior to the generation of neurons or glial cells, NSCs are already committed to generate region-specific subtypes, e.g., excitatory projection neurons in the cerebral cortex. The second fate restriction is temporal, with neurons of deep cortical layers generated earlier than neurons of the upper layers of the mammalian neocortex (Molyneaux et al., 2007). Indeed, transplantation experiments revealed that early NSCs have the potential to generate neurons of all cortex layers while late NSCs loose the potential to generate deep layer neurons (Frantz and McConnell, 1996), suggesting progressive fate restriction in regard to neuronal subtype specification. As recently confirmed with new tools for clonal analysis (Gao et al., 2014), this occurs via an asymmetric mode of division, by which a NSC generates sequentially different neuronal subtypes sometimes directly and sometimes via intermediate, transit-amplifying progenitor cells. Only after generating all these neurons, the NSC eventually switches to generate glial cells. Thus, the developmental time point predicts whether the stem cell progeny commits to a neuronal or a glial fate (Götz et al., 2016). Not well-understood is, however, how the sequential fate specification is achieved, how the previous fates are repressed and how new lineages are installed.

DNA modifications have been attributed diverse roles in this process. For example, it has been suggested that gliogenesis occurs late, because glial genes are repressed during most of neurogenesis by DNA methylation (Takizawa et al., 2001). This finding could be expanded to the concept that cellular methylomes define cell identities directly (Figure 4B). A certain combination of DNA methylation marks might safeguard the faithful expression of adequate cellular programs, while simultaneously repressing inappropriate transcriptional networks (Figure 4B) (Lee et al., 2014). Accordingly, temporal changes in DNA methylation may then also allow the sequence of neuronal fates generated during development (Figure 4A) (Takizawa et al., 2001; Sanosaka et al., 2009). In agreement with this is the recent finding that human GABAergic interneurons and glutamatergic projection neurons indeed differ vastly in their distribution of DNA modifications (Kozlenkov et al., 2016). This concept of DNA-methylation fixing fates and repressing alternatives predicts ectopic fates to be generated upon interference with DNMTs or TETs, and we will see below that evidence from mouse mutants does not support this prediction.

But first we will consider another important role for DNA methylation, where its repressive role is clearly evident, namely repressing endogenous retroviral elements (ERVs, Groh and Schotta, 2017). In all mammalian cells, the highest proportion of DNA methylation is found on repetitive regions, representing transposons, retrotransposons, or sequences derived from these (Crichton et al., 2014). Therefore, it has been frequently suggested that the main function of DNA methylation might be to silence these intragenomic parasites (Yoder et al., 1997). However, these elements might also have important roles during neurogenesis (Figure 4C). On one hand active transposition could contribute (Erwin et al., 2014), on the other many regulatory elements in the genome are evolved from or influenced by endogenous retroviruses (ERVs) domesticated for gene expression (Rebollo et al., 2012; Fasching et al., 2015). Thus, it is not unlikely that genome protective and gene-regulatory roles of DNA methylation follow similar principles. It has been suggested that ERVs contribute to the enormous neuronal diversity and plasticity of the neuronal lineage (Rebollo et al., 2012; Erwin et al., 2014). Epigenetic mechanisms control ERV activity and thus regulate local chromatin remodeling, transcription and potentially their translocation (Figure 4C). This would imply an important evolutional role to the pronounced increase of viral elements in the genome during mammalian phylogeny. However, there are only few experimental options to unequivocally assess the function of DNA modifications during cortical development and thus to strengthen these hypotheses, including: the characterization of the availability of the enzymatic machinery during development; the epigenomic analysis of DNA modifications during cortical neurogenesis; and finally, the use of genetically modified mouse models, possessing altered amounts or distribution of DNA modifications.

\section{Expression of the DNA Modifying Machinery during Cerebral Cortex Neurogenesis}

The developing as well as the adult brain expresses most proteins implicated in the regulation of DNA modifications. Dnmt1 is ubiquitously present in fetal and full grown mouse brains (Goto et al., 1994); i.e., even in postmitotic neurons and glia. But also the de novo methyltransferases are detectable in the nervous system. Dnmt3a is prominently expressed e.g., in neural stem and progenitor cells of the ventricular and subventricular zone of the developing cerebral cortex (E10.5-E17.5), as well as in postnatal neurons and the oligodendrocyte lineage (Moyon et al., 2016), while it is mostly absent in astrocytes (Feng et al., 2005). Dnmt3b can only be detected in the SVZ early (E10.5-13.5), not later during development (E15.5) (Feng et al., 2005; Moyon et al., 2016). The newly discovered rodent Dnmt3c lacks expression in brain as far as we know (Barau et al., 2016). Neural expression of the three Tet proteins has been reported as well (Khoueiry et al., 2017), with Tet3 most dominant and Tet1 most feeble, and 
with little modulation between newborn and adults (Szulwach et al., 2011) or brain regions (Szwagierczak et al., 2010), but dynamic changes during oligodendrocyte differentiation (Zhao et al., 2014). Interestingly, Tet3 expression has been found to be amplified by synaptic activity in cultured hippocampal neurons (Yu et al., 2015). Additionally, many methyl binding proteins are present in the nervous system, sometimes in remarkably selective patterns. A typical example is Mbd1, expressed commonly in neurons, but not detectable in astrocytes (Zhao et al., 2003). Thus, the availability and the (at least partially) dynamic expression of the DNA methylation and de-methylation machinery during cell fate commitment and differentiation is indeed in line with potential roles for this epigenomic mark in these processes.

\section{Epigenomic Distribution of DNA Modifications during Neurogenesis}

First indications about the cell type specific distribution and dynamics of DNA methylation during neurogenesis (and its relation to other epigenomic marks and transcription factor binding) have been gained from differentiation of embryonic stem cells or neural progenitor cells (Meissner et al., 2008; Stadler et al., 2011). Profiling of pluripotent and neural stem cells revealed for example, that regions with low methylation show the most dynamic DNA methylation changes during development. Moreover, these are frequently overlapping with regulatory sequences of important cell fate factors (like Pax6) and are dependent on transcription factor activity in some tested cases, as DNA binding (of the neural repressor REST for example) is necessary and sufficient to evade high DNA methylation levels on its binding sites (Stadler et al., 2011).

The recent development of affordable technology for DNA methylome analysis made the investigation of human brain samples practicable as well (Figure 2). Large cohorts of human prefrontal cortex samples revealed the dynamic changes occurring during development and aging of the brain (Hernandez et al., 2011; Numata et al., 2012; Jaffe et al., 2016). These studies indicate that, although methylation differences are occurring in different scales, either at individual CpGs, at differentially methylated regions (DMRs) or at even larger domains, most changes are established during development and childhood, while methylomes are less plastic later in life. These findings likely point to differences in cellular composition rather than developmental dynamics and thus demonstrate the predicaments when heterogeneous cell populations are examined. Analysis of more homogeneous cell populations allow deeper insights, e.g., revealing how in the developing and adult frontal cortex $5 \mathrm{mC}$ patterns distinguish cell types (Lister et al., 2013) or that methylated $\mathrm{CpH}$ sites are almost absent from (NeuN negative) non-neuronal cells (Lister et al., 2013). Instead, $\mathrm{CpH}$ methylation is generated de novo during neuronal maturation both in mouse and human cells (Lister et al., 2013; Guo et al., 2014) and parallels synaptogenesis and neuronal diversity (Lister et al., 2013; Mo et al., 2015). Remarkably, studies also indicate that methylation marks occurring in regulatory regions are more indicative of transcriptional repression when falling on $\mathrm{CpH}$ rather than on $\mathrm{CpG}$ sites (Mo et al., 2015). The first characterization of $5 \mathrm{hmC}$ dynamics was linked to the development of reliable methods mapping this mark epigenome-wide (Figure 2). Using hMeDIP for example has shown that in contrast to $5 \mathrm{mC}$, the cellular amount of $5 \mathrm{hmC}$ is significantly increasing when neural stem and progenitor cells are differentiating to neurons (Hahn et al., 2013). A similar developmental dynamic has also been detected during ex vivo analysis of mouse cortices and human brain samples (Szulwach et al., 2011; Lister et al., 2013; Wen et al., 2014; Vogel Ciernia and LaSalle, 2016). Interestingly, newly acquired $5 \mathrm{hmC}$ often associates with regulatory elements of neuronal genes (Szulwach et al., 2011; Wang et al., 2012) and are solely detectable at CpG sites (Lister et al., 2013). Bisulfite sequencing of DNA derived from adult mouse dentate granule neurons before and after synchronous neuronal activation in vivo, revealed that some DNA methylation marks do not behave as stable as commonly expected and rather suggested that around $1 \%$ of analyzed $5 \mathrm{mC}$ sites fulfill the criteria of activity induced de-methylation (Guo et al., 2011) with yet elusive function. Taken together profiling of DNA methylation in mammalian brain cells from both in vitro and ex vivo models indicate that diverse cell populations differ significantly in their methylome and that these changes can swiftly emerge at meaningful sites, indicating that they could contribute to shape cellular functions.

\section{Mouse Models}

Genetically modified mouse models of all known writers of the DNA methylation machinery have been generated to functionally test the global relevance of this epigenomic modification. The full knockout for the de novo methyltransferase Dnmt3a for example appears overall normal at birth (Li et al., 1992; Okano et al., 1999), but mice die 4 weeks after birth due to multiple developmental defects (Okano et al., 1999). It has been suggested that this is in part due to a disturbed neurogenesis in the SEZ of the forebrain and the hippocampal dentate gyrus, as NSCs loose DNA methylation on the gene bodies of neuronal genes and fail to activate those during differentiation ( $\mathrm{Wu}$ et al., 2010). While defects in adult neurogenesis are unlikely to cause death of the entire organism, these data did reveal a key role of DNA-methylation in NSC differentiation with a clear decrease in postnatal neurogenesis. The authors also suggest that this was due to an increase in gliogenesis and hence a fate switch, but this is less clear as postnatal and adult NSCs also express astroglial markers, such as GFAP and some level of S100b (Beckervordersandforth et al., 2010), making it impossible to decide whether the increased cell population are NSCs or astrocytes. Conditional deletions of Dnmt3a in the developing nervous system (Nes1-Cre) have been reported to have a shortened lifespan as well, which has been attributed to postnatal motor neuron loss (Nguyen et al., 2007). Mouse embryos lacking Dnmt3b exhibit multiple developmental abnormalities, including rostral neural tube defects, and are not delivered to term (Okano et al., 1999). Thus, normal neural development is (at least partially) dependent on the presence of both de novo methyltransferases. Although full knockouts of 
Tet1 have been reported to be born overall normal (Dawlaty et al., 2011), recently new mutant alleles have been generated that are lethal during embryogenesis when outbred, at least partially due to "deformities in forebrain development associated with incomplete closure of the anterior neuropore" (Khoueiry et al., 2017).

Dnmtl full knockout embryos have strong phenotypes and are early embryonic lethal (Li et al., 1992), while conditional deletions show a remarkably specific effect. Depletion of this methyltransferase in postmitotic neurons, using the CamK-Cre line, neither affected DNA methylation levels significantly, nor influenced postnatal survival of the animals, raising questions, which role Dnmtl expression might play in postmitotic cells (Fan et al., 2001). Deletion of Dnmtl in neural progenitors during development results in animal death (hours after birth in animals with high recombination rates; and significant neuronal loss in animals with reduced Cre activity) (Fan et al., 2001). Although after deletion of DNMT1 in the developing CNS upregulation of some glial genes, like GFAP, have been observed, this occurred only at the end of neurogenesis and hence onset of gliogenesis in vivo, despite much earlier loss of DNMT1 using the Nestin-Cre line (Fan et al., 2005). Importantly, genomewide expression analysis should reveal best whether true fate changes occur-nowadays ideally done at single cell level. However, RNA-seq data do not reveal any indication for a fate switch when done early (E15 cortex Emx1 ${ }^{\mathrm{Cre}} / \mathrm{Uhrf1}$, Ramesh et al., 2016) and highlight rather neuronal death as the main phenotypic consequence of hypomethylation in the brain and the GFAP increase as an indication of gliosis due to postnatal neuronal cell death when done later (Hutnick et al., 2009; Ramesh et al., 2016). Cortical degeneration appears not to be a consequence of altered fates, but rather due to another key role of DNA methylation: to stably silence repetitive elements [for Dnmt1 in particular ERVs like the intracisternal Aparticle retroviruses (IAPs); (Walsh et al., 1998; Hutnick et al., 2009)]. Conditional deletions of the Dnmt1 partner Uhrf1 during cortical neurogenesis confirmed these findings and showed that despite profound demethylation primarily IAPs were derepressed and that this is accompanied by postnatal neuronal degeneration (Ramesh et al., 2016). Interestingly, IAPs were up-regulated already at E12, yet neuronal death occurred only after the first postnatal week when neurons become functionally active. Indeed, many genes encoding for proteins involved in neuronal activity were dysregulated supporting again a role of DNA methylation in regulating neronal differentiation processes. Notably, despite loss of at least $25 \%$ of global DNA methylation no ectopic fates such as premature gliogenesis were observed in these mutants. Moreover the data indicated, that it is not the loss of DNA methylation, but rather the gain of $5 \mathrm{hmC}$, which results in IAP activation during brain development, since the process can be rescued by simultaneous reduction of Tet 2 and Tet3 (Ramesh et al., 2016). Thus, depleting key enzymes for DNA methylation maintenance or removal throws the epigenome out of balance, resulting in rather specific consequences for neuronal maturation and survival (Figure 4D). Similar to the phenotypes observed in brain development, deletion of DNMT1 in the retina and in oligodendrocyte progenitor cells show profound defects in the final maturation of photoreceptors and oligodendrocytes, respectively, but no generation of alternative fates (Table $\mathbf{1}$ ).

Development continues to some extent also in the adult brain, both in adult neurogenesis but also in the ongoing synaptic plasticity that constantly re-forms new synaptic connections. DNA modifications have also accredited functional roles in these processes including information storage and providing (in adult NSC niches) new mature neurons (Ninkovic and Götz, 2013). In the late 60s, an open debate was started, how neurons would be able store memory information for life, while the stability of the molecular building blocks of these cells is many orders of magnitudes shorter. Interestingly, DNA modifications, due to their mode of inheritance, have been frequently suggested as prime candidates for memory storage (Griffith and Mahler, 1969; Crick, 1984). Already in 1969 J.S. Griffith suggested "that the physical basis of memory could lie in the enzymatic modification of the DNA of nerve cells. It might be worth looking to see if there are unusual bases specific to nerve cell DNA, but in the absence of evidence to that effect, a plausible suggestion would be that the modification consists of methylation (or demethylation)" (Griffith and Mahler, 1969). During the last decades this concept has been regularly revived (Meagher, 2014). Indeed we know now, that the brain is, compared to other organs, especially active in remodeling DNA methylation patterns and a prominent source of scarce DNA modifications. For example, non-CpG methylation is common in neurons in contrast to other differentiated cell types (Guo et al., 2014), its occurrence is highly linked to the neuronal expression of Dnmt3a, as knockdown of this de novo methyltransferase abolishes $\mathrm{CpH}$ methylation (but not $\mathrm{CpG}$ methylation, which is mainly dependent on Dnmt1) (Guo et al., 2014). However, maybe the most surprising results stem from genetically modified, overexpression or knockdown mouse models of writer, reader, and eraser proteins of DNA modifications, resulting either in phenotypes affecting memory formation or consolidation [Tetl (Kaas et al., 2013; Rudenko et al., 2013; Zhang et al., 2013), Dnmt1, Dnmt3a, and Dnmt3a2 (Miller and Sweatt, 2007; Feng et al., 2010; Oliveira et al., 2012, 2016)], emotional or maternal behavior [Dnmt3a (LaPlant et al., 2010), Mbd2 (Hendrich et al., 2001)], LTP [Mbd1 (Zhao et al., 2003)], or adult neurogenesis in the hippocampus [GADD45b (Ma et al., 2009), Tet1 (Zhang et al., 2013), Mbd1 (Zhao et al., 2003), Mecp2 (Smrt et al., 2007)] indicating that neuronal maturation or specific neuronal functions in particular neuronal plasticity might indeed be dependent on normal availability of the DNA modification machinery.

\section{Human Model Systems of DNA Modifications and Brain Diseases}

Interestingly, several neurodevelopmental disorders have also been linked to proteins involved in the regulation of DNA modification emphasizing their relevance in cerebral cortex development. Rett syndrome, a rare X-linked postnatal neurological disorder, was the first among this group, when it was discovered in 1999 that it is caused by mutations in the DNA methylation binding protein MeCP2 (Amir et al., 1999). In the meantime many more diseases have been added: for 
example, the immunodeficiency, centromeric region instability, and facial anomalies syndrome (ICF), caused by mutations in DNMT3B is often associated with mild cognitive and neurologic defects (Hagleitner et al., 2008). Similarly, childhood overgrowth syndrome, a developmental disorder resulting (amongst other phenotypes) in intellectual disabilities, is caused by mutations of the DNMT3A gene (Tatton-Brown et al., 2014). Moreover, it has been recently shown that brain tumors, use stem cell factors to interfere with astrocyte differentiation and the DNA methylation machinery (Bulstrode et al., 2017). Indeed some brain tumors are even driven by mutations in the isocitrate dehydrogenase 1 (IDH1). Mutations of this enzyme result in tumor cells which contain severely elevated global levels of DNA methylation. The reason for this is the abnormal accumulation of 2-hydroxyglutarate (2-HG), a powerful inhibitor of TET activity (Turcan et al., 2012). Thus, DNA methylation clearly also affects human NSC differentiation even though much more needs to be learnt about the exact mechanisms.

\section{OUTLOOK}

Taken together, the above mentioned experimental tests on the role of DNA methylation in cerebral cortex development do not lend much support to the model that it serves to repress alternative fates (Table 2). Besides GFAP up-regulation (Kim et al., 2016) there is not much evidence for aberrant glial fate instruction, including in genome-wide expression analysis (Hutnick et al., 2009; Ramesh et al., 2016), and no ectopic fate choices have been observed in any of the above mutants. Rather, a common theme is cell death, due to either the failure to fully differentiate and/or to repress repetitive elements (Ramesh et al., 2016), quite similar to what had been described in the postnatal retina (Rhee et al., 2012). Thus, the hypothesis that DNA methylation represses alternative fates has to be questioned, while the role in differentiation receives more support. Indeed, in the few studies of mouse mutants that examined the transcriptome, many aspects of immature cells, such as cell proliferation, fail to be repressed at later stages along with the failure to upregulate genes involved in synaptic maturation. According to $\mathrm{Wu}$ et al., Prc2 mediated mechanisms could be involved in these processes as they showed that Dnmt3a-mediated DNA methylation adjacent to $\mathrm{H} 3 \mathrm{~K} 4 \mathrm{me} 3$ high promoters interferes with Prc2 binding and H3K27me3 and thereby mediates upregulation of neuronal progenitor genes (Wu et al., 2010). In addition or alternatively, Tet-mediated roles could be involved as described above from the Uhrf1 study (Ramesh et al., 2016). However, much remains to be understood about the repressive function of DNA-methylation in regard to differentiation and neuronal maturation. This is particularly evident from the poor correlation between changes in DNA-methylation and transcription. Further follow-up studies on the transcriptional changes that are crucial for the phenotypes aiming to correlate these to epigenetic mechanisms will hold the key to better mechanistic understanding of the mouse mutant phenotypes.

Indeed, so far virtually none of these phenotypes have been linked with precise sites in the genome being de-methylated, but always groups of sites, regions, or genes. This can be confounding as for example many methylation marks might have opposing roles in the body, such as maternal and paternal imprints that, respectively, reduce or activate growth (Barlow and Bartolomei, 2014). Thus, to elucidate which roles the epigenome plays in the brain, first we have to differentiate essential from specific and both from bystander marks, dissecting thereby secondary from causal DNA modifications. This can now be done by new options, which allow manipulating individual DNA modifications to evaluate their immediate causal effect on transcription and cell behavior. This new experimental field, collectively termed epigenome editing (Stricker et al., 2017), promises to deliver a better understanding of the role DNA modifications play during cortex development. Epigenome editing is mainly based on modified versions of the bacterial CRISPR system, allowing to precisely target any genomic locus in any cell. Fusing DNA modifying enzymes to dCas9 (the nuclease deficient targeting protein) has been proven to locally set or remove DNA modifications. So far, Tet1 and Dnmt3a have been used most prominently to show that DNA methylation on the accurate locus can indeed influence transcription of a gene close by (Amabile et al., 2016; Choudhury et al., 2016; Liu et al., 2016; Xu et al., 2016). However, we are still far from a comprehensive view about gene regulation by DNA modifications, especially during brain development, but studies successfully manipulating histone marks indicate this will be promising approach to study neurogenesis (Albert et al., 2017). Thus, tools of epigenetic engineering allowing methylating or demethylating specific genomic sites to investigate their function directly will help to causally link methylation of specific genes with functional phenotypes. This aim is more relevant than ever, as epigenome wide association studies (EWAS) suggest new targets for a variety of diseases on a regular basis (Stricker et al., 2017).

\section{CONCLUSION}

While much remains to be done, experimental tests propose already a revision of the concept that DNA methylation would repress alternative fates (Tables 1, 2). Rather DNA methylation appears generally required for repression of ERVs, even though with striking cell type specificity. A further general concept that emerged is its role in orchestrating cell differentiation, but within a given lineage (neurons, oligodendrocyte progenitors, Table 2). The involvement of splicing as effector of changes in DNA methylation is an exciting new angle to pursue with more precise epigenetic engineering tools. Distinguishing essential from specific, and causal from secondary marks will be essential for neuro-epigenetics. New approaches promise to answer long outstanding questions and will likely facilitate the discovery that DNA modifications might have new unexpected roles in the brain.

\section{AUTHOR CONTRIBUTIONS}

All authors listed have made a substantial, direct and intellectual contribution to the work, and approved it for publication. 


\section{FUNDING}

This work was supported by an Advanced European Research Council grant (ChroNeuroRepair GA no. 340793);

\section{REFERENCES}

Albert, M., Kalebic, N., Florio, M., Lakshmanaperumal, N., Haffner, C., Brandl, H., et al. (2017). Epigenome profiling and editing of neocortical progenitor cells during development. EMBO J. 36, 2642-2658. doi: 10.15252/embj.201796764

Amabile, A., Migliara, A., Capasso, P., Biffi, M., Cittaro, D., Naldini, L., et al. (2016). Inheritable silencing of endogenous genes by hit-and-run targeted epigenetic editing. Cell 167, 219.e14-232.e14. doi: 10.1016/j.cell.2016.09.006

Amir, R. E., Van den Veyver, I. B., Wan, M., Tran, C. Q., Francke, U., and Zoghbi, H. Y. (1999). Rett syndrome is caused by mutations in X-linked MECP2, encoding methyl-CpG-binding protein 2. Nat. Genet. 23, 185-188. doi: $10.1038 / 13810$

Avery, O. T., Macleod, C. M., and McCarty, M. (1944). Studies on the chemical nature of the substance inducing transformation of pneumococcal types : induction of transformation by a desoxyribonucleic acid fraction isolated from pneumococcus type III. J. Exp. Med. 79, 137-158. doi: 10.1084/jem.79.2.137

Bachman, M., Uribe-Lewis, S., Yang, X., Burgess, H. E., Iurlaro, M., Reik, W., et al. (2015). 5-Formylcytosine can be a stable DNA modification in mammals. Nat. Chem. Biol. 11, 555-557. doi: 10.1038/nchembio. 1848

Bachman, M., Uribe-Lewis, S., Yang, X., Williams, M., Murrell, A., and Balasubramanian, S. (2014). 5-Hydroxymethylcytosine is a predominantly stable DNA modification. Nat. Chem. 6, 1049-1055. doi: 10.1038/nchem.2064

Bahar Halpern, K., Vana, T., and Walker, M. D. (2014). Paradoxical role of DNA methylation in activation of FoxA2 gene expression during endoderm development. J. Biol. Chem. 289, 23882-23892. doi: 10.1074/jbc.M114.5 73469

Barau, J., Teissandier, A., Zamudio, N., Roy, S., Nalesso, V., Herault, Y., et al. (2016). The DNA methyltransferase DNMT3C protects male germ cells from transposon activity. Science 354, 909-912. doi: 10.1126/science.aah5143

Barlow, D. P., and Bartolomei, M. S. (2014). Genomic imprinting in mammals. Cold Spring Harb. Perspect. Biol. 6:a018382. doi: 10.1101/cshperspect.a018382

Barlow, D. P., Stoger, R., Herrmann, B. G., Saito, K., and Schweifer, N. (1991). The mouse insulin-like growth factor type-2 receptor is imprinted and closely linked to the Tme locus. Nature 349, 84-87. doi: 10.1038/349084a0

Bartolomei, M. S., Zemel, S., and Tilghman, S. M. (1991). Parental imprinting of the mouse H19 gene. Nature 351, 153-155. doi: 10.1038/351153a0

Baubec, T., Ivanek, R., Lienert, F., and Schubeler, D. (2013). Methylationdependent and -independent genomic targeting principles of the MBD protein family. Cell 153, 480-492. doi: 10.1016/j.cell.2013.03.011

Beckervordersandforth, R., Tripathi, P., Ninkovic, J., Bayam, E., Lepier, A., Stempfhuber, B., et al. (2010). In vivo fate mapping and expression analysis reveals molecular hallmarks of prospectively isolated adult neural stem cells. Cell Stem Cell 7, 744-758. doi: 10.1016/j.stem.2010.11.017

Bell, A. C., and Felsenfeld, G. (2000). Methylation of a CTCF-dependent boundary controls imprinted expression of the Igf2 gene. Nature 405, 482-485. doi: 10.1038/35013100

Bernstein, B. E., Meissner, A., and Lander, E. S. (2007). The mammalian epigenome. Cell 128, 669-681. doi: 10.1016/j.cell.2007.01.033

Bhutani, N., Brady, J. J., Damian, M., Sacco, A., Corbel, S. Y., and Blau, H. M. (2010). Reprogramming towards pluripotency requires AID-dependent DNA demethylation. Nature 463, 1042-1047. doi: 10.1038/nature08752

Bhutani, N., Burns, D. M., and Blau, H. M. (2011). DNA demethylation dynamics. Cell 146, 866-872. doi: 10.1016/j.cell.2011.08.042

Bird, A. (2002). DNA methylation patterns and epigenetic memory. Genes Dev. 16, 6-21. doi: 10.1101/gad.947102

Booth, M. J., Raiber, E. A., and Balasubramanian, S. (2015). Chemical methods for decoding cytosine modifications in DNA. Chem. Rev. 115, 2240-2254. doi: $10.1021 /$ cr5002904

Bulstrode, H., Johnstone, E., Marques-Torrejon, M. A., Ferguson, K. M., Bressan, R. B., Blin, C., et al. (2017). Elevated FOXG1 and SOX2 in glioblastoma enforces
Sonderforschungsbereich (SFB)870; the Bavarian Research Network For IPs; the Helmholtz Association; the Deutsche Forschungsgemeinschaft, and the Munich Cluster for Systems Neurology (EXC 1010 SyNergy). neural stem cell identity through transcriptional control of cell cycle and epigenetic regulators. Genes Dev. 31, 757-773. doi: 10.1101/gad.293027.116

Busslinger, M., Hurst, J., and Flavell, R. A. (1983). DNA methylation and the regulation of globin gene expression. Cell 34, 197-206. doi: 10.1016/0092-8674(83)90150-2

Chao, M. P., Gentles, A. J., Chatterjee, S., Lan, F., Reinisch, A., Corces, M. R., et al. (2017). Human AML-iPSCs reacquire leukemic properties after differentiation and model clonal variation of disease. Cell Stem Cell 20, 329.e7-344.e7. doi: 10.1016/j.stem.2016.11.018

Chen, P., Jeannotte, R., and Weimer, B. C. (2014). Exploring bacterial epigenomics in the next-generation sequencing era: a new approach for an emerging frontier. Trends Microbiol. 22, 292-300. doi: 10.1016/j.tim.2014.03.005

Chen, T., Ueda, Y., Xie, S., and Li, E. (2002). A novel Dnmt3a isoform produced from an alternative promoter localizes to euchromatin and its expression correlates with active de novo methylation. J. Biol. Chem. 277, 38746-38754. doi: 10.1074/jbc.M205312200

Choudhury, S. R., Cui, Y., Lubecka, K., Stefanska, B., and Irudayaraj, J. (2016). CRISPR-dCas9 mediated TET1 targeting for selective DNA demethylation at BRCA1 promoter. Oncotarget 7, 46545-46556. doi: 10.18632/oncotarget.10234

Cortazar, D., Kunz, C., Selfridge, J., Lettieri, T., Saito, Y., MacDougall, E., et al. (2011). Embryonic lethal phenotype reveals a function of TDG in maintaining epigenetic stability. Nature 470, 419-423. doi: 10.1038/nature09672

Crichton, J. H., Dunican, D. S., Maclennan, M., Meehan, R. R., and Adams, I. R. (2014). Defending the genome from the enemy within: mechanisms of retrotransposon suppression in the mouse germline. Cell. Mol. Life Sci. 71, 1581-1605. doi: 10.1007/s00018-013-1468-0

Crick, F. (1984). Memory and molecular turnover. Nature 312:101. doi: $10.1038 / 312101 \mathrm{a} 0$

Dawlaty, M. M., Breiling, A., Le, T., Barrasa, M. I., Raddatz, G., Gao, Q., et al. (2014). Loss of Tet enzymes compromises proper differentiation of embryonic stem cells. Dev. Cell 29, 102-111. doi: 10.1016/j.devcel.2014.03.003

Dawlaty, M. M., Breiling, A., Le, T., Raddatz, G., Barrasa, M. I., Cheng, A. W., et al. (2013). Combined deficiency of Tet1 and Tet2 causes epigenetic abnormalities but is compatible with postnatal development. Dev. Cell 24, 310-323. doi: 10.1016/j.devcel.2012.12.015

Dawlaty, M. M., Ganz, K., Powell, B. E., Hu, Y. C., Markoulaki, S., Cheng, A. W., et al. (2011). Tet1 is dispensable for maintaining pluripotency and its loss is compatible with embryonic and postnatal development. Cell Stem Cell 9, 166-175. doi: 10.1016/j.stem.2011.07.010

Domcke, S., Bardet, A. F., Adrian Ginno, P., Hartl, D., Burger, L., and Schubeler D. (2015). Competition between DNA methylation and transcription factors determines binding of NRF1. Nature 528, 575-579. doi: 10.1038/nature16462

Erwin, J. A., Marchetto, M. C., and Gage, F. H. (2014). Mobile DNA elements in the generation of diversity and complexity in the brain. Nat. Rev. Neurosci. 15, 497-506. doi: 10.1038/nrn3730

Fan, G., Beard, C., Chen, R. Z., Csankovszki, G., Sun, Y., Siniaia, M., et al. (2001). DNA hypomethylation perturbs the function and survival of CNS neurons in postnatal animals. J. Neurosci. 21, 788-797.

Fan, G., Martinowich, K., Chin, M. H., He, F., Fouse, S. D., Hutnick, L., et al. (2005). DNA methylation controls the timing of astrogliogenesis through regulation of JAK-STAT signaling. Development 132, 3345-3356. doi: 10.1242/dev.01912

Fang, J., Cheng, J., Wang, J., Zhang, Q., Liu, M., Gong, R., et al. (2016). Hemimethylated DNA opens a closed conformation of UHRF1 to facilitate its histone recognition. Nat. Commun. 7:11197. doi: 10.1038/ncomms11197

Fasching, L., Kapopoulou, A., Sachdeva, R., Petri, R., Jonsson, M. E., Manne, C., et al. (2015). TRIM28 represses transcription of endogenous retroviruses in neural progenitor cells. Cell Rep. 10, 20-28. doi: 10.1016/j.celrep.2014.12.004

Feng, J., Chang, H., Li, E., and Fan, G. (2005). Dynamic expression of de novo DNA methyltransferases Dnmt3a and Dnmt3b in the central nervous system. J. Neurosci. Res. 79, 734-746. doi: 10.1002/jnr.20404 
Feng, J., Zhou, Y., Campbell, S. L., Le, T., Li, E., Sweatt, J. D., et al. (2010). Dnmt1 and Dnmt3a maintain DNA methylation and regulate synaptic function in adult forebrain neurons. Nat. Neurosci. 13, 423-430. doi: 10.1038/nn.2514

Ferguson-Smith, A. C., Cattanach, B. M., Barton, S. C., Beechey, C. V., and Surani, M. A. (1991). Embryological and molecular investigations of parental imprinting on mouse chromosome 7, Nature 351, 667-670. doi: $10.1038 / 351667 \mathrm{a} 0$

Frantz, G. D., and McConnell, S. K. (1996). Restriction of late cerebral cortical progenitors to an upper-layer fate. Neuron 17, 55-61. doi: 10.1016/S0896-6273(00)80280-9

Frauer, C., Hoffmann, T., Bultmann, S., Casa, V., Cardoso, M. C., Antes, I., et al. (2011). Recognition of 5-hydroxymethylcytosine by the Uhrf1 SRA domain. PLoS ONE 6:e21306. doi: 10.1371/journal.pone.0021306

Gabel, H. W., Kinde, B., Stroud, H., Gilbert, C. S., Harmin, D. A., Kastan, N. R., et al. (2015). Disruption of DNA-methylation-dependent long gene repression in Rett syndrome. Nature 522, 89-93. doi: 10.1038/nature14319

Gao, P., Postiglione, M. P., Krieger, T. G., Hernandez, L., Wang, C., Han, Z., et al. (2014). Deterministic progenitor behavior and unitary production of neurons in the neocortex. Cell 159, 775-788. doi: 10.1016/j.cell.2014.10.027

Goll, M. G., Kirpekar, F., Maggert, K. A., Yoder, J. A., Hsieh, C. L., Zhang, X., et al. (2006). Methylation of tRNAAsp by the DNA methyltransferase homolog Dnmt2. Science 311, 395-398. doi: 10.1126/science.1120976

Goto, K., Numata, M., Komura, J. I., Ono, T., Bestor, T. H., and Kondo, H. (1994). Expression of DNA methyltransferase gene in mature and immature neurons as well as proliferating cells in mice. Differentiation 56, 39-44. doi: 10.1046/j.1432-0436.1994.56120039.x

Götz, M., Nakafuku, M., and Petrik, D. (2016). Neurogenesis in the developing and adult brain-similarities and key differences. Cold Spring Harb. Perspect. Biol. 8:396. doi: 10.1101/cshperspect.a018853

Greer, E. L., Blanco, M. A., Gu, L., Sendinc, E., Liu, J., Aristizabal-Corrales, D., et al. (2015). DNA methylation on N6-adenine in C. elegans. Cell 161, 868-878. doi: 10.1016/j.cell.2015.04.005

Griffith, J. S., and Mahler, H. R. (1969). DNA ticketing theory of memory. Nature 223, 580-582. doi: 10.1038/223580a0

Groh, S., and Schotta, G. (2017). Silencing of endogenous retroviruses by heterochromatin. Cell. Mol. Life Sci. 74, 2055-2065. doi: 10.1007/s00018-017-2454-8

Guo, J. U., Ma, D. K., Mo, H., Ball, M. P., Jang, M. H., Bonaguidi, M. A., et al. (2011). Neuronal activity modifies the DNA methylation landscape in the adult brain. Nat. Neurosci. 14, 1345-1351. doi: 10.1038/nn.2900

Guo, J. U., Su, Y., Shin, J. H., Shin, J., Li, H., Xie, B., et al. (2014). Distribution, recognition and regulation of non-CpG methylation in the adult mammalian brain. Nat. Neurosci. 17, 215-222. doi: 10.1038/nn.3607

Hagleitner, M. M., Lankester, A., Maraschio, P., Hulten, M., Fryns, J. P., Schuetz, C., et al. (2008). Clinical spectrum of immunodeficiency, centromeric instability and facial dysmorphism (ICF syndrome). J. Med. Genet. 45, 93-99. doi: 10.1136/jmg.2007.053397

Hahn, M. A., Qiu, R., Wu, X., Li, A. X., Zhang, H., Wang, J., et al. (2013). Dynamics of 5-hydroxymethylcytosine and chromatin marks in Mammalian neurogenesis. Cell Rep. 3, 291-300. doi: 10.1016/j.celrep.2013.01.011

Harrisson, C. M. (1971). The arrangement of chromatin in the interphase nucleus with reference to cell differentiation and repression in higher organisms. Tissue Cell 3, 523-550. doi: 10.1016/S0040-8166(71)80001-0

He, Y. F., Li, B. Z., Li, Z., Liu, P., Wang, Y., Tang, Q., et al. (2011). Tet-mediated formation of 5-carboxylcytosine and its excision by TDG in mammalian DNA. Science 333, 1303-1307. doi: 10.1126/science.1210944

Hendrich, B., and Bird, A. (1998). Identification and characterization of a family of mammalian methyl-CpG binding proteins. Mol. Cell. Biol. 18, 6538-6547. doi: 10.1128/MCB.18.11.6538

Hendrich, B., Guy, J., Ramsahoye, B., Wilson, V. A., and Bird, A. (2001). Closely related proteins $\mathrm{MBD} 2$ and $\mathrm{MBD} 3$ play distinctive but interacting roles in mouse development. Genes Dev. 15, 710-723. doi: 10.1101/gad.194101

Hernandez, D. G., Nalls, M. A., Gibbs, J. R., Arepalli, S., van der Brug, M., Chong, S., et al. (2011). Distinct DNA methylation changes highly correlated with chronological age in the human brain. Hum. Mol. Genet. 20, 1164-1172. doi: $10.1093 / \mathrm{hmg} / \mathrm{ddq} 561$
Holliday, R., and Pugh, J. E. (1975). DNA modification mechanisms and gene activity during development. Science 187, 226-232. doi: $10.1126 /$ science. 1111098

Hon, G. C., Rajagopal, N., Shen, Y., McCleary, D. F., Yue, F., Dang, M. D., et al. (2013). Epigenetic memory at embryonic enhancers identified in DNA methylation maps from adult mouse tissues. Nat. Genet. 45, 1198-1206. doi: $10.1038 /$ ng. 2746

Horvath, S. (2013). DNA methylation age of human tissues and cell types. Genome Biol. 14:R115. doi: 10.1186/gb-2013-14-10-r115

Hotchkiss, R. D. (1948). The quantitative separation of purines, pyrimidines, and nucleosides by paper chromatography. J. Biol. Chem. 175, 315-332.

Hu, S., Wan, J., Su, Y., Song, Q., Zeng, Y., Nguyen, H. N., et al. (2013). DNA methylation presents distinct binding sites for human transcription factors. Elife 2:e00726. doi: 10.7554/eLife.00726

Hutnick, L. K., Golshani, P., Namihira, M., Xue, Z., Matynia, A., Yang, X. W., et al. (2009). DNA hypomethylation restricted to the murine forebrain induces cortical degeneration and impairs postnatal neuronal maturation. Hum. Mol. Genet. 18, 2875-2888. doi: 10.1093/hmg/ddp222

Irizarry, R. A., Ladd-Acosta, C., Wen, B., Wu, Z., Montano, C., Onyango, P., et al. (2009). The human colon cancer methylome shows similar hypo- and hypermethylation at conserved tissue-specific CpG island shores. Nat. Genet. 41, 178-186. doi: 10.1038/ng.298

Ito, S., Shen, L., Dai, Q., Wu, S. C., Collins, L. B., Swenberg, J. A., et al. (2011). Tet proteins can convert 5-methylcytosine to 5-formylcytosine and 5-carboxylcytosine. Science 333, 1300-1303. doi: 10.1126/science.1210597

Iurlaro, M., Ficz, G., Oxley, D., Raiber, E. A., Bachman, M., Booth, M. J., et al. (2013). A screen for hydroxymethylcytosine and formylcytosine binding proteins suggests functions in transcription and chromatin regulation. Genome Biol. 14:R119. doi: 10.1186/gb-2013-14-10-r119

Jaffe, A. E., Gao, Y., Deep-Soboslay, A., Tao, R., Hyde, T. M., Weinberger, D. R., et al. (2016). Mapping DNA methylation across development, genotype and schizophrenia in the human frontal cortex. Nat. Neurosci. 19, 40-47. doi: $10.1038 / \mathrm{nn} .4181$

Jones, P. A., Wolkowicz, M. J., Rideout, W. M. III, Gonzales, F. A., Marziasz, C. M., Coetzee, G. A., et al. (1990). De novo methylation of the MyoD1 CpG island during the establishment of immortal cell lines. Proc. Natl. Acad. Sci. U.S.A. 87, 6117-6121. doi: 10.1073/pnas.87.16.6117

Kaas, G. A., Zhong, C., Eason, D. E., Ross, D. L., Vachhani, R. V., Ming, G. L., et al. (2013). TET1 controls CNS 5-methylcytosine hydroxylation, active DNA demethylation, gene transcription, and memory formation. Neuron 79, 1086-1093. doi: 10.1016/j.neuron.2013.08.032

Khoueiry, R., Sohni, A., Thienpont, B., Luo, X., Velde, J. V., Bartoccetti, M., et al. (2017). Lineage-specific functions of TET1 in the postimplantation mouse embryo. Nat. Genet. 49, 1061-1072. doi: 10.1038/ng.3868

Kiecker, C., and Lumsden, A. (2005). Compartments and their boundaries in vertebrate brain development. Nat. Rev. Neurosci. 6, 553-564. doi: $10.1038 / \mathrm{nrn} 1702$

Kim, H., Jang, W. Y., Kang, M. C., Jeong, J., Choi, M., Sung, Y., et al. (2016). TET1 contributes to neurogenesis onset time during fetal brain development in mice. Biochem. Biophys. Res. Commun. 471, 437-443. doi: 10.1016/j.bbrc.2016.02.060

Kozlenkov, A., Wang, M., Roussos, P., Rudchenko, S., Barbu, M., Bibikova, M., et al. (2016). Substantial DNA methylation differences between two major neuronal subtypes in human brain. Nucleic Acids Res. 44, 2593-2612. doi: $10.1093 /$ nar/gkv1304

Kriaucionis, S., and Heintz, N. (2009). The nuclear DNA base 5hydroxymethylcytosine is present in Purkinje neurons and the brain. Science 324, 929-930. doi: 10.1126/science.1169786

LaPlant, Q., Vialou, V., Covington, H. E. III, Dumitriu, D., Feng, J., Warren, B. L., et al. (2010). Dnmt3a regulates emotional behavior and spine plasticity in the nucleus accumbens. Nat. Neurosci. 13, 1137-1143. doi: 10.1038/nn.2619

Lee, H. J., Hore, T. A., and Reik, W. (2014). Reprogramming the methylome: erasing memory and creating diversity. Cell Stem Cell 14, 710-719. doi: 10.1016/j.stem.2014.05.008

Li, E., Bestor, T. H., and Jaenisch, R. (1992). Targeted mutation of the DNA methyltransferase gene results in embryonic lethality. Cell 69, 915-926. doi: 10.1016/0092-8674(92)90611-F 
Lister, R., Mukamel, E. A., Nery, J. R., Urich, M., Puddifoot, C. A., Johnson, N. D., et al. (2013). Global epigenomic reconfiguration during mammalian brain development. Science 341:1237905. doi: 10.1126/science.1237905

Lister, R., Pelizzola, M., Dowen, R. H., Hawkins, R. D., Hon, G., Tonti-Filippini, J., et al. (2009). Human DNA methylomes at base resolution show widespread epigenomic differences. Nature 462, 315-322. doi: 10.1038/nature08514

Liu, X. S., Wu, H., Ji, X., Stelzer, Y., Wu, X., Czauderna, S., et al. (2016). Editing DNA methylation in the mammalian genome. Cell 167, 233.e17-247.e17. doi: 10.1016/j.cell.2016.08.056

Lock, L. F., Melton, D. W., Caskey, C. T., and Martin, G. R. (1986). Methylation of the mouse hprt gene differs on the active and inactive X chromosomes. Mol. Cell. Biol. 6, 914-924. doi: 10.1128/MCB.6.3.914

Lyko, F., Ramsahoye, B. H., and Jaenisch, R. (2000). DNA methylation in Drosophila melanogaster. Nature 408, 538-540. doi: 10.1038/35046205

Lyle, R., Watanabe, D., te Vruchte, D., Lerchner, W., Smrzka, O. W., Wutz, A., et al. (2000). The imprinted antisense RNA at the Igf2r locus overlaps but does not imprint Mas1. Nat. Genet. 25, 19-21. doi: 10.1038/75546

Ma, D. K., Jang, M. H., Guo, J. U., Kitabatake, Y., Chang, M. L., Pow-Anpongkul, N., et al. (2009). Neuronal activity-induced Gadd45b promotes epigenetic DNA demethylation and adult neurogenesis. Science 323, 1074-1077. doi: 10.1126/science.1166859

Masserdotti, G., Gascon, S., and Götz, M. (2016). Direct neuronal reprogramming: learning from and for development. Development 143, 2494-2510. doi: $10.1242 /$ dev.092163

Meagher, R. B. (2014). 'Memory and molecular turnover', 30 years after inception. Epigenetics Chromatin 7:37. doi: 10.1186/1756-8935-7-37

Meissner, A., Mikkelsen, T. S., Gu, H., Wernig, M., Hanna, J., Sivachenko, A., et al. (2008). Genome-scale DNA methylation maps of pluripotent and differentiated cells. Nature 454, 766-770. doi: 10.1038/nature07107

Mellen, M., Ayata, P., Dewell, S., Kriaucionis, S., and Heintz, N. (2012). MeCP2 binds to $5 \mathrm{hmC}$ enriched within active genes and accessible chromatin in the nervous system. Cell 151, 1417-1430. doi: 10.1016/j.cell.2012.11.022

Messerschmidt, D. M., Knowles, B. B., and Solter, D. (2014). DNA methylation dynamics during epigenetic reprogramming in the germline and preimplantation embryos. Genes Dev. 28, 812-828. doi: $10.1101 / \operatorname{gad} .234294 .113$

Miller, C. A., and Sweatt, J. D. (2007). Covalent modification of DNA regulates memory formation. Neuron 53, 857-869. doi: 10.1016/j.neuron.2007.02.022

Mo, A., Mukamel, E. A., Davis, F. P., Luo, C., Henry, G. L., Picard, S., et al. (2015). Epigenomic signatures of neuronal diversity in the mammalian brain. Neuron 86, 1369-1384. doi: 10.1016/j.neuron.2015.05.018

Molyneaux, B. J., Arlotta, P., Menezes, J. R., and Macklis, J. D. (2007). Neuronal subtype specification in the cerebral cortex. Nat. Rev. Neurosci. 8, 427-437. doi: $10.1038 / \mathrm{nrn} 2151$

Moyon, S., Huynh, J. L., Dutta, D., Zhang, F., Ma, D., Yoo, S., et al. (2016). Functional characterization of DNA methylation in the oligodendrocyte lineage. Cell Rep. 15, 748-760. doi: 10.1016/j.celrep.2016.03.060

Moyon, S., Ma, D., Huynh, J. L., Coutts, D. J. C., Zhao, C., Casaccia, P., et al. (2017). Efficient remyelination requires DNA methylation. eNeuro 4, 1-12. doi: 10.1523/ENEURO.0336-16.2017

Munzel, M., Globisch, D., Bruckl, T., Wagner, M., Welzmiller, V., Michalakis, S., et al. (2010). Quantification of the sixth DNA base hydroxymethylcytosine in the brain. Angew. Chem. Int. Ed Engl. 49, 5375-5377. doi: 10.1002/anie.201002033

Nabel, C. S., Jia, H., Ye, Y., Shen, L., Goldschmidt, H. L., Stivers, J. T., et al. (2012). AID/APOBEC deaminases disfavor modified cytosines implicated in DNA demethylation. Nat. Chem. Biol. 8, 751-758. doi: 10.1038/nchembio.1042

Nguyen, S., Meletis, K., Fu, D., Jhaveri, S., and Jaenisch, R. (2007). Ablation of de novo DNA methyltransferase Dnmt3a in the nervous system leads to neuromuscular defects and shortened lifespan. Dev. Dyn. 236, 1663-1676. doi: $10.1002 /$ dvdy. 21176

Niesen, M. I., Osborne, A. R., Yang, H., Rastogi, S., Chellappan, S., Cheng, J. Q., et al. (2005). Activation of a methylated promoter mediated by a sequence-specific DNA-binding protein, RFX. J. Biol. Chem. 280, 38914-38922. doi: 10.1074/jbc.M504633200

Ninkovic, J., and Götz, M. (2013). Fate specification in the adult brainlessons for eliciting neurogenesis from glial cells. Bioessays 35, 242-252. doi: 10.1002/bies. 201200108
Noguchi, H., Kimura, A., Murao, N., Matsuda, T., Namihira, M., and Nakashima, K. (2015). Expression of DNMT1 in neural stem/precursor cells is critical for survival of newly generated neurons in the adult hippocampus. Neurosci. Res. 95, 1-11. doi: 10.1016/j.neures.2015.01.014

Numata, S., Ye, T., Hyde, T. M., Guitart-Navarro, X., Tao, R., Wininger, M., et al. (2012). DNA methylation signatures in development and aging of the human prefrontal cortex. Am. J. Hum. Genet. 90, 260-272. doi: 10.1016/j.ajhg.2011.12.020

Okano, M., Bell, D. W., Haber, D. A., and Li, E. (1999). DNA methyltransferases Dnmt3a and Dnmt3b are essential for de novo methylation and mammalian development. Cell 99, 247-257. doi: 10.1016/S0092-8674(00)81656-6

Oliveira, A. M., Hemstedt, T. J., and Bading, H. (2012). Rescue of aging-associated decline in Dnmt3a2 expression restores cognitive abilities. Nat. Neurosci. 15, 1111-1113. doi: 10.1038/nn.3151

Oliveira, A. M., Hemstedt, T. J., Freitag, H. E., and Bading, H. (2016). Dnmt3a2: a hub for enhancing cognitive functions. Mol. Psychiatry 21, 1130-1136. doi: $10.1038 / \mathrm{mp} .2015 .175$

Ooi, S. K., and Bestor, T. H. (2008). The colorful history of active DNA demethylation. Cell 133, 1145-1148. doi: 10.1016/j.cell.2008.06.009

Ooi, S. K., Qiu, C., Bernstein, E., Li, K., Jia, D., Yang, Z., et al. (2007). DNMT3L connects unmethylated lysine 4 of histone $\mathrm{H} 3$ to de novo methylation of DNA. Nature 448, 714-717. doi: 10.1038/nature05987

Penn, N. W., Suwalski, R., O’Riley, C., Bojanowski, K., and Yura, R. (1972). The presence of 5-hydroxymethylcytosine in animal deoxyribonucleic acid. Biochem. J. 126, 781-790. doi: 10.1042/bj1260781

Plongthongkum, N., Diep, D. H., and Zhang, K. (2014). Advances in the profiling of DNA modifications: cytosine methylation and beyond. Nat. Rev. Genet. 15, 647-661. doi: 10.1038/nrg3772

Privat, E., and Sowers, L. C. (1996). Photochemical deamination and demethylation of 5-methylcytosine. Chem. Res. Toxicol. 9, 745-750. doi: 10.1021/tx950182o

Prokhortchouk, A., Hendrich, B., Jorgensen, H., Ruzov, A., Wilm, M., Georgiev, G., et al. (2001). The p120 catenin partner Kaiso is a DNA methylation-dependent transcriptional repressor. Genes Dev. 15, 1613-1618. doi: 10.1101/gad.1 98501

Rai, K., Huggins, I. J., James, S. R., Karpf, A. R., Jones, D. A., and Cairns, B. R. (2008). DNA demethylation in zebrafish involves the coupling of a deaminase, a glycosylase, and gadd45. Cell 135, 1201-1212. doi: 10.1016/j.cell.2008.11.042

Ramesh, V., Bayam, E., Cernilogar, F. M., Bonapace, I. M., Schulze, M., Riemenschneider, M. J., et al. (2016). Loss of Uhrf1 in neural stem cells leads to activation of retroviral elements and delayed neurodegeneration. Genes Dev. 30, 2199-2212. doi: 10.1101/gad.284992.116

Rebollo, R., Romanish, M. T., and Mager, D. L. (2012). Transposable elements: an abundant and natural source of regulatory sequences for host genes. Annu. Rev. Genet. 46, 21-42. doi: 10.1146/annurev-genet-110711-155621

Reik, W., Dean, W., and Walter, J. (2001). Epigenetic reprogramming in mammalian development. Science 293, 1089-1093. doi: 10.1126/science. 1063443

Rhee, K. D., Yu, J., Zhao, C. Y., Fan, G., and Yang, X. J. (2012). Dnmt1-dependent DNA methylation is essential for photoreceptor terminal differentiation and retinal neuron survival. Cell Death Dis. 3:e427. doi: 10.1038/cddis.2012.165

Riggs, A. D. (1975). X inactivation, differentiation, and DNA methylation. Cytogenet. Cell Genet. 14, 9-25. doi: 10.1159/000130315

Rudenko, A., Dawlaty, M. M., Seo, J., Cheng, A. W., Meng, J., Le, T., et al. (2013). Tet1 is critical for neuronal activity-regulated gene expression and memory extinction. Neuron 79, 1109-1122. doi: 10.1016/j.neuron.2013.08.003

Sadakierska-Chudy, A., Kostrzewa, R. M., and Filip, M. (2015). A comprehensive view of the epigenetic landscape part I: DNA methylation, passive and active DNA demethylation pathways and histone variants. Neurotox. Res. 27, 84-97. doi: 10.1007/s12640-014-9497-5

Sanosaka, T., Namihira, M., and Nakashima, K. (2009). Epigenetic mechanisms in sequential differentiation of neural stem cells. Epigenetics 4, 89-92. doi: 10.4161/epi.4.2.8233

Scarano, E. (1971). The control of gene function in cell differentiation and in embryogenesis. Adv. Cytopharmacol. 1, 13-24.

Seidl, C. I., Stricker, S. H., and Barlow, D. P. (2006). The imprinted air ncRNA is an atypical RNAPII transcript that evades splicing and escapes nuclear export. EMBO J. 25, 3565-3575. doi: 10.1038/sj.emboj.7601245 
Shin, J., Ming, G. L., and Song, H. (2014). DNA modifications in the mammalian brain. Philos. Trans. R. Soc. Lond. B Biol. Sci. 369:20130512. doi: 10.1098/rstb.2013.0512

Singer-Sam, J., Grant, M., LeBon, J. M., Okuyama, K., Chapman, V., Monk, M., et al. (1990). Use of a HpaII-polymerase chain reaction assay to study DNA methylation in the Pgk-1 CpG island of mouse embryos at the time of X-chromosome inactivation. Mol. Cell. Biol. 10, 4987-4989. doi: 10.1128/MCB.10.9.4987

Singh, R. K., Mallela, R. K., Hayes, A., Dunham, N. R., Hedden, M. E., Enke, R. A., et al. (2017). Dnmt1, Dnmt3a and Dnmt3b cooperate in photoreceptor and outer plexiform layer development in the mammalian retina. Exp. Eye Res. 159, 132-146. doi: 10.1016/j.exer.2016.11.014

Smrt, R. D., Eaves-Egenes, J., Barkho, B. Z., Santistevan, N. J., Zhao, C., Aimone, J. B., et al. (2007). Mecp2 deficiency leads to delayed maturation and altered gene expression in hippocampal neurons. Neurobiol. Dis. 27, 77-89. doi: 10.1016/j.nbd.2007.04.005

Spruijt, C. G., Gnerlich, F., Smits, A. H., Pfaffeneder, T., Jansen, P. W., Bauer, C., et al. (2013). Dynamic readers for 5-(hydroxy)methylcytosine and its oxidized derivatives. Cell 152, 1146-1159. doi: 10.1016/j.cell.2013.02.004

Stadler, M. B., Murr, R., Burger, L., Ivanek, R., Lienert, F., Scholer, A., et al. (2011). DNA-binding factors shape the mouse methylome at distal regulatory regions. Nature 480, 490-495. doi: 10.1038/nature10716

Stricker, S. H., Feber, A., Engstrom, P. G., Caren, H., Kurian, K. M., Takashima, Y., et al. (2013). Widespread resetting of DNA methylation in glioblastomainitiating cells suppresses malignant cellular behavior in a lineage-dependent manner. Genes Dev. 27, 654-669. doi: 10.1101/gad.212662.112

Stricker, S. H., Koferle, A., and Beck, S. (2017). From profiles to function in epigenomics. Nat. Rev. Genet. 18, 51-66. doi: 10.1038/nrg.2016.138

Szulwach, K. E., Li, X., Li, Y., Song, C. X., Wu, H., Dai, Q., et al. (2011). 5-hmCmediated epigenetic dynamics during postnatal neurodevelopment and aging. Nat. Neurosci. 14, 1607-1616. doi: 10.1038/nn.2959

Szwagierczak, A., Bultmann, S., Schmidt, C. S., Spada, F., and Leonhardt, H. (2010). Sensitive enzymatic quantification of 5-hydroxymethylcytosine in genomic DNA. Nucleic Acids Res. 38:e181. doi: 10.1093/nar/gkq684

Tahiliani, M., Koh, K. P., Shen, Y., Pastor, W. A., Bandukwala, H., Brudno, Y., et al. (2009). Conversion of 5-methylcytosine to 5-hydroxymethylcytosine in mammalian DNA by MLL partner TET1. Science 324, 930-935. doi: $10.1126 /$ science. 1170116

Takahashi, K., and Yamanaka, S. (2016). A decade of transcription factormediated reprogramming to pluripotency. Nat. Rev. Mol. Cell Biol. 17, 183-193. doi: $10.1038 / \mathrm{nrm} .2016 .8$

Takizawa, T., Nakashima, K., Namihira, M., Ochiai, W., Uemura, A., Yanagisawa, M., et al. (2001). DNA methylation is a critical cell-intrinsic determinant of astrocyte differentiation in the fetal brain. Dev. Cell 1, 749-758. doi: 10.1016/S1534-5807(01)00101-0

Tate, P. H., and Bird, A. P. (1993). Effects of DNA methylation on DNAbinding proteins and gene expression. Curr. Opin. Genet. Dev. 3, 226-231. doi: 10.1016/0959-437X(93)90027-M

Tatton-Brown, K., Seal, S., Ruark, E., Harmer, J., Ramsay, E., del Vecchio Duarte, S., et al. (2014). Mutations in the DNA methyltransferase gene DNMT3A cause an overgrowth syndrome with intellectual disability. Nat. Genet. 46, 385-388. doi: $10.1038 /$ ng. 2917

Turcan, S., Rohle, D., Goenka, A., Walsh, L. A., Fang, F., Yilmaz, E., et al. (2012). IDH1 mutation is sufficient to establish the glioma hypermethylator phenotype. Nature 483, 479-483. doi: 10.1038/nature10866

Vogel Ciernia, A., and LaSalle, J. (2016). The landscape of DNA methylation amid a perfect storm of autism aetiologies. Nat. Rev. Neurosci. 17, 411-423. doi: 10.1038/nrn.2016.41

Waddington, C. H. (1957). The Strategy of the Genes; A Discussion of Some Aspects of Theoretical Biology. London: Allen \& Unwin.

Walsh, C. P., Chaillet, J. R., and Bestor, T. H. (1998). Transcription of IAP endogenous retroviruses is constrained by cytosine methylation. Nat. Genet. 20, 116-117. doi: 10.1038/2413

Wang, T., Pan, Q., Lin, L., Szulwach, K. E., Song, C. X., He, C., et al. (2012). Genome-wide DNA hydroxymethylation changes are associated with neurodevelopmental genes in the developing human cerebellum. Hum. Mol. Genet. 21, 5500-5510. doi: 10.1093/hmg/dds394
Watson, J. D., and Crick, F. H. (1953). Molecular structure of nucleic acids; a structure for deoxyribose nucleic acid. Nature 171, 737-738. doi: $10.1038 / 171737 \mathrm{a} 0$

Weber, M., Davies, J. J., Wittig, D., Oakeley, E. J., Haase, M., Lam, W. L., et al. (2005). Chromosome-wide and promoter-specific analyses identify sites of differential DNA methylation in normal and transformed human cells. Nat. Genet. 37, 853-862. doi: 10.1038/ng1598

Wen, L., Li, X., Yan, L., Tan, Y., Li, R., Zhao, Y., et al. (2014). Wholegenome analysis of 5-hydroxymethylcytosine and 5-methylcytosine at base resolution in the human brain. Genome Biol. 15:R49. doi: 10.1186/gb-2014-153-r49

Wu, H., Coskun, V., Tao, J., Xie, W., Ge, W., Yoshikawa, K., et al. (2010). Dnmt3a-dependent nonpromoter DNA methylation facilitates transcription of neurogenic genes. Science 329, 444-448. doi: 10.1126/science.11 90485

Wu, S. C., and Zhang, Y. (2010). Active DNA demethylation: many roads lead to Rome. Nat. Rev. Mol. Cell Biol. 11, 607-620. doi: 10.1038/nr $\mathrm{m} 2950$

Wu, T. P., Wang, T., Seetin, M. G., Lai, Y., Zhu, S., Lin, K., et al. (2016). DNA methylation on $\mathrm{N}(6)$-adenine in mammalian embryonic stem cells. Nature 532, 329-333. doi: 10.1038/nature17640

Xie, W., Barr, C. L., Kim, A., Yue, F., Lee, A. Y., Eubanks, J., et al. (2012). Base-resolution analyses of sequence and parent-of-origin dependent DNA methylation in the mouse genome. Cell 148, 816-831. doi: 10.1016/j.cell.2011.12.035

Xu, X., Tao, Y., Gao, X., Zhang, L., Li, X., Zou, W., et al. (2016). A CRISPRbased approach for targeted DNA demethylation. Cell Discov 2:16009. doi: 10.1038 /celldisc.2016.9

Yoder, J. A., Walsh, C. P., and Bestor, T. H. (1997). Cytosine methylation and the ecology of intragenomic parasites. Trends Genet. 13, 335-340. doi: 10.1016/S0168-9525(97)01181-5

Yu, H., Su, Y., Shin, J., Zhong, C., Guo, J. U., Weng, Y. L., et al. (2015). Tet3 regulates synaptic transmission and homeostatic plasticity via DNA oxidation and repair. Nat. Neurosci. 18, 836-843. doi: 10.1038/nn.4008

Yu, M., Hon, G. C., Szulwach, K. E., Song, C. X., Zhang, L., Kim, A., et al. (2012). Base-resolution analysis of 5-hydroxymethylcytosine in the mammalian genome. Cell 149, 1368-1380. doi: 10.1016/j.cell.2012.04.027

Zhang, G., Huang, H., Liu, D., Cheng, Y., Liu, X., Zhang, W., et al. (2015). N6-methyladenine DNA modification in Drosophila. Cell 161, 893-906. doi: $10.1016 /$ j.cell.2015.04.018

Zhang, L., Lu, X., Lu, J., Liang, H., Dai, Q., Xu, G. L., et al. (2012). Thymine DNA glycosylase specifically recognizes 5-carboxylcytosine-modified DNA. Nat. Chem. Biol. 8, 328-330. doi: 10.1038/nchembio.914

Zhang, R. R., Cui, Q. Y., Murai, K., Lim, Y. C., Smith, Z. D., Jin, S., et al. (2013). Tet1 regulates adult hippocampal neurogenesis and cognition. Cell Stem Cell 13 237-245. doi: 10.1016/j.stem.2013.05.006

Zhao, X., Dai, J., Ma, Y., Mi, Y., Cui, D., Ju, G., et al. (2014). Dynamics of teneleven translocation hydroxylase family proteins and 5-hydroxymethylcytosine in oligodendrocyte differentiation. Glia 62, 914-926. doi: 10.1002/glia.22649

Zhao, X., Ueba, T., Christie, B. R., Barkho, B., McConnell, M. J., Nakashima, K., et al. (2003). Mice lacking methyl-CpG binding protein 1 have deficits in adult neurogenesis and hippocampal function. Proc. Natl. Acad. Sci. U.S.A. 100, 6777-6782. doi: 10.1073/pnas.1131928100

Zhu, H., Wang, G., and Qian, J. (2016). Transcription factors as readers and effectors of DNA methylation. Nat. Rev. Genet. 17, 551-565. doi: $10.1038 / \mathrm{nrg} .2016 .83$

Conflict of Interest Statement: The authors declare that the research was conducted in the absence of any commercial or financial relationships that could be construed as a potential conflict of interest.

Copyright (๑) 2018 Stricker and Götz. This is an open-access article distributed under the terms of the Creative Commons Attribution License (CC BY). The use, distribution or reproduction in other forums is permitted, provided the original author(s) and the copyright owner are credited and that the original publication in this journal is cited, in accordance with accepted academic practice. No use, distribution or reproduction is permitted which does not comply with these terms. 